\title{
A semi-analytical approach to model drilling fluid leakage into fractured formation
}

\author{
Rami Albattat ${ }^{1} \cdot$ Hussein Hoteit $^{1}$ (i) \\ Received: 19 December 2020 / Revised: 27 April 2021 / Accepted: 29 April 2021 / Published online: 22 May 2021 \\ (C) The Author(s) 2021
}

\begin{abstract}
Loss of circulation while drilling is a challenging problem that may interrupt operations and contaminate the subsurface formation. Analytical modeling of fluid flow in fractures is a tool that can be quickly deployed to assess drilling mud leakage into fractures. A new semi-analytical solution is developed to model the flow of non-Newtonian drilling fluid in fractured formation. The model is applicable for various fluid types exhibiting yield-power law (Herschel-Bulkley). We use finite-element simulations to verify our solutions. We also generate type curves and compare them to others in the literature. We then demonstrate the applicability of the proposed model for two field cases encountering lost circulations. To address the subsurface uncertainty, we combine the semi-analytical solutions with Monte Carlo and generate probabilistic predictions. The solution method can estimate the range of fracture conductivity, parametrized by the fracture hydraulic aperture, and time-dependent fluid loss rate that can predict the cumulative volume of lost fluid.
\end{abstract}

Keywords Lost circulation $\cdot$ Mud leakage $\cdot$ Herschel-Bulkley $\cdot$ Analytical solution $\cdot$ Type curves $\cdot$ Non-Newtonian fluids

\section{Introduction}

Naturally fractured formation is often prone to severe mud loss during drilling operations. As a result, problems may emanate because of the severity of lost fluid such as kicks, wellbore instability, formation damage, and sometimes freshwater aquifer contamination (Al-Hameedi et al. 2019; Seyedmohammadi 2017). One procedure to encounter and mitigate this problem is to add lost circulation material (LCM) to the drilling fluid. LCM is commonly used in drilling applications to reduce and stop lost circulation (Attong et al. 1995; Ali et al. 1997; Olsen et al. 2019; Knudsen et al. 2015). The fluid characteristics of LCM, such as density and viscosity, should be carefully selected based on the formation of hydraulic properties such as the conductivity of the thief layers and fractures, among other factors (Luzardo et al. 2015; Wang et al. 2020; Okoro et al. 2020; $\mathrm{He}$ and $\mathrm{Bu} 2020$ ). Due to the time-scale of the problem, there is a need to develop accurate and efficient modeling tools applicable to real-time drilling

Hussein Hoteit

hussein.hoteit@kaust.edu.sa

1 King Abdullah University of Science and Technology (KAUST), Thuwal, Saudi Arabia operations to perform diagnostics and predictions. Field observations suggest that, during mud filtration into porous media, an immediate spurt loss generally occurs, which then decreases in rate as filter cake is being deposited.

On the other hand, mud loss rate into fractures often exhibits a sudden peak, followed by a gradual declining loss (Dyke et al. 1995). The transient rate decline is related to the fluid pressure build-up within the fracture. The ultimate lost volume is a function of the fluid mobilities, and the fracture conductivity, pore volume, and extension (Norman 2011). Analytical solutions for mud loss into a single effective fracture, mimicking a fractured formation, have been studied for decades in the literature. Early modeling attempts for simplified cases were based on Darcy's Law at steady-state conditions (Bannister and Lawson 1985; Bruckdorfer and Gleit 1988). Sanfillippo et al. (1997) introduced a semi-analytical solution for Newtonian fluid flow into a horizontal fracture by combining the diffusivity equation and mass conservation in one-dimensional (1D) radial systems. The derived ordinary differential equation (ODE) was solved numerically. Maglione and Marsala (1997) presented an analytical solution of the diffusivity equation for fluids with a constant viscosity at the steady-state conditions. Liétard et al. (2002) developed type curves based on numerical solutions to describe timedependent mud-loss volumes into a horizontal fracture. The 
model is applicable for non-Newtonian fluids exhibiting Bingham-Plastic rheological behavior. The authors generated type curves, based on dimensionless groups, to describe mudloss rates as a function of the fracture hydraulic aperture and fluid properties. Other authors proposed analytical approaches to generate similar type curves to the ones proposed by Liétard et al. (2002). Kemerli and Engin (2020) evaluated the analytical and numerical modeling of the flow of Herschel-Bulkley fluid model in a monotube. Huang et al. (2011) derived a method to estimate the hydraulic fracture aperture by simplifying insignificant terms in the governing equations. Majidi et al. (2010) generated approximate analytical solutions for yield-power law fluids by reducing a Tylor expansion of the governing nonlinear flow equation into its linear terms. This approximation helped to generate an analytical solution but was found to introduce inaccuracies in some cases, as discussed in the paper. Motivated by the work of Majidi et al. (2010), Dokhani et al. (2020) introduced a mathematical model and numerical solutions to account for fluid leak-off from fractures. Russian et al. (2019) used stochastic and global sensitivity analysis to study drilling mud losses in fractured media. Other authors proposed various numerical methods based on higher-order discretizations (Ambartsumyan et al. 2019; Girault and Rivière 2009; Arbogast and Brunson 2007; Shao et al. 2016; Țene et al. 2016; Hoteit and Firoozabadi 2008).

In this work, a new semi-analytical solution is developed to model the flow of non-Newtonian drilling or LCM fluids exhibiting a yield-power law (Herschel-Bulkley) behavior. The non-Newtonian fluid flow is described by the Cauchy momentum equation. The nonlinear system of equations is reformulated and converted into a system of ODEs, which is then solved numerically with an efficient ODE solver (Hindmarsh et al. 2005). For convenience, we also introduce dimensionless groups and develop type curves, which describe fluid volume loss behavior versus dimensionless time, as a function of the fracture and fluid properties. The fracture is represented by two parallel plates in a $1 \mathrm{D}$ radial system. We use high-resolution finite element simulations from commercial software, COMSOL (Littmarck and Saeidi 1986), to verify our model. We also compare our proposed semi-analytical solutions to two other models from the literature. The developed type curves describe the mud-loss volume and mudinvasion front velocity under various fluid rheological properties, drilling pressure conditions, and fracture aperture. We use the type curves and demonstrate the applicability of the proposed model for two field cases. We discuss a simple approach to combine the developed semi-analytical solutions with Monte Carlo simulations to address uncertainties.

This paper is organized as follows; we first review the main governing equation for non-Newtonian fluid flow. Then, we reformulate the equations for $1 \mathrm{D}$ radial system, followed by a discussion of the solution method of the obtained semi- analytical system. In "Physical and mathematical model," we compare our solution to other analytical solutions for a particular fluid-type case. For general cases, we verify our solutions with full physics numerical simulations. In the "Discussion" section, we introduce new type curves with the corresponding dimensionless groups. In "Conclusions," before the conclusion, we demonstrate the applicability of the proposed approach for two field cases.

\section{Physical and mathematical model}

The general governing equation used to describe nonNewtonian fluid dynamics is given by Cauchy equation (Irgens 2014; Cioranescu et al. 2016), such that,

$\rho \frac{\partial \mathbf{v}}{\partial t}+\rho(\mathbf{v} \cdot \nabla) \mathbf{v}=\nabla(-p \mathbf{I}+\boldsymbol{\tau})+\rho \mathbf{g}$

In the above equation, the transient term consists of the fluid density $\rho$, velocity vector $\mathbf{v}$, and time $t$. The fluid pressure is denoted by $p$, the fluid shear stress by $\tau$, the gravitational acceleration by $\mathbf{g}$, and the identity matrix by $\mathbf{I}$.

The fracture is represented by two parallel radial plates, perpendicular to the wellbore, as shown in Fig. 1. Note that horizontal fractures could occur at shallow depths and overpressurized formations (Smith and Montgomery 2015; BenAvraham et al. 2012).

Assuming steady-state conditions and neglecting gravity with low inertial effect in comparison to other forces, Eq. (1) becomes,

$0=\nabla \cdot(-p \mathbf{I}+\boldsymbol{\tau})$

In $1 \mathrm{D}$ radial system $r$, the above equation simplifies to (Panton 1984),

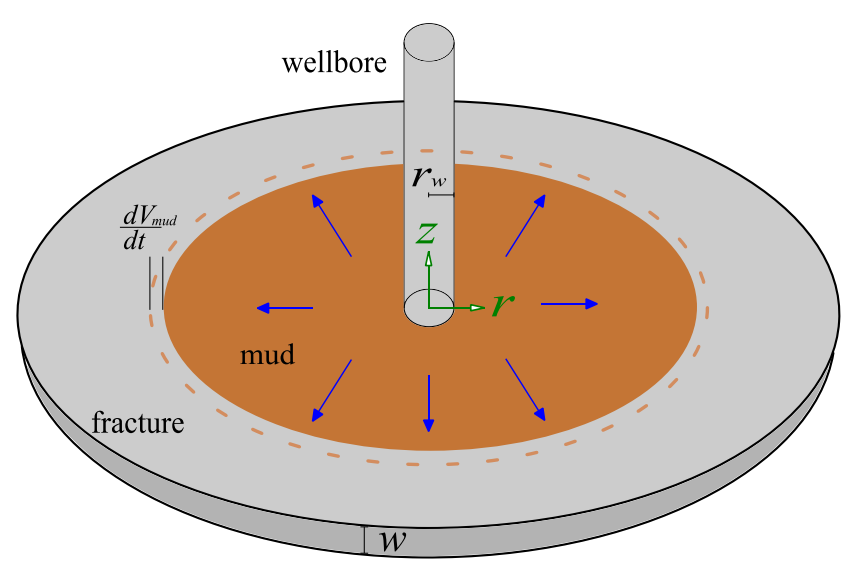

Fig. 1 Physical domain mimicking a horizontal fracture intercepting the wellbore. The shaded brown area shows the mud radial invasion, $r_{w}$ is wellbore radius, $w$ is fracture aperture, and $V_{\text {mud }}$ is mud-loss volume 


$$
\tau(z, r)=z \frac{\partial p}{\partial r}
$$

where $\tau(z, r)$ is the radial shear stress component, perpendicular to the $Z$-direction.

On the other hand, the shear stress component $\tau$ is described by the Herschel-Bulkley fluid model (Hemphil et al. 1993), that is,

$\boldsymbol{\tau}(z, r)=\boldsymbol{\tau}_{0}+m\left(\frac{d v_{r}}{d z}\right)^{n}$

In Eq. (4), the parameter $\tau_{0}$ is the yield shear stress, which determines the fluidity state, as explained later. The flow index $n$ is a positive number that reflects fluid rheological behavior. For instance, the fluid exhibits shear-thinning behavior when $n<1$, and shear-thickening when $n>1$. Typical values for flow behavioral index in drilling fluid range from about 0.3 to 1.0 (Kelessidis et al. 2006). The other parameters correspond to the consistency multiplier $m$, and the derivative of the radial velocity $v_{r}$ in the $Z$-direction, reflecting the shear rate. Note that the Herschel-Bulkley model in Eq. (4) can also be used to describe Newtonian fluids when considering $\tau_{0}+0$ and $n=1$.

\section{Solution method}

Our system of equations is given by the Cauchy equation (3) and the Herschel-Bulkley fluid model equation (4). The first equation combines two external forces, pressure force and shear force, applied to the fluid. The second equation describes the fluid rheological behavior as a function of the fluid yield stress and shear rate. The proposed solution is based on the assumption that the drilling fluid viscosity is higher than the in situ water viscosity in the fracture, with no significant mixing between the two fluids. Under these conditions, a piston-like displacement is considered at the mud-water interfaces, which is a reasonable assumption (Razavi et al. 2017). Therefore, the fluid pressure and the shear force are approximated only within the mud invaded zone. The fracture is assumed infinite acting with constant average hydraulic aperture, and no-slip boundary conditions (B.C.) are set at the fracture walls. The pressure is assumed to be constant at the inlet.

The concept of the proposed solution method is illustrated in Fig. 2. As the fluid propagates deep into the fracture, radial flow velocity decreases and shear stress diminishes. The shear rate is highest in the vicinity of the wellbore and gradually reduces away from the wellbore. Therefore, the fluid apparent viscosity increases as the shear rate decreases with the radial distance. Furthermore, driven by the vertical variations of flow velocity and shear stress, fluid layers along the fracture aperture develop and introduce selffriction with the highest intensity at the fracture wall and reduce linearly toward the fracture centerline, as illustrated in Fig. 2. Consequently, a region with diminished shear rate (i.e., $d v_{r} / d z=0$ ) develops at the fracture center, corresponding to the yield shear stress zone $\tau_{0}$ (see Eq. (4)). This region is denoted by the plug flow region, while the rest is the free flow region. As the fluid propagates further within the fracture, the plug region expands toward the fracture walls, eventually reaching a total stall of the flow, as illustrated in Fig. 3a. This condition represents the ultimate steady state, where the pressure drop between the wellbore and the mud front becomes too small to overcome the yield stress $\tau_{0}$ (see Fig. 3b).

The fluid flow in the fracture is symmetrical across the fracture centerline. Therefore, we derive the equations for the domain upper half of symmetry. Based on the previous discussion, where we subdivided the flow domain into two regions a plug and a free region, the following conditions are introduced for the velocity vector:

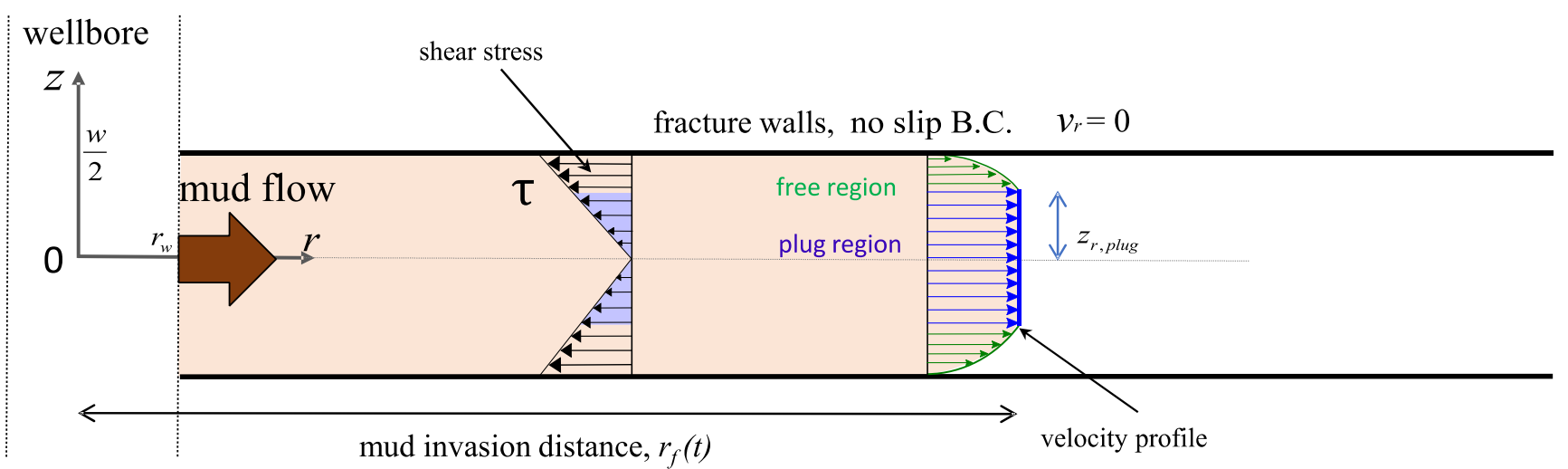

Fig. 2 Sketch of an infinite-acting fracture cross-section of aperture $w$, intercepting the wellbore. No-flow and no-slip B.C. are imposed at the fracture wall. $r_{f}(t)$ is the time-dependent radial distance of the invading fluid into the fracture; $v_{r}$ is the velocity vector, and $\tau$ is the shear stress.

The plug flow region corresponds to the region where the variation of the velocity along the $z$-axis diminishes; the free flow region corresponds to the region outside the plug region 


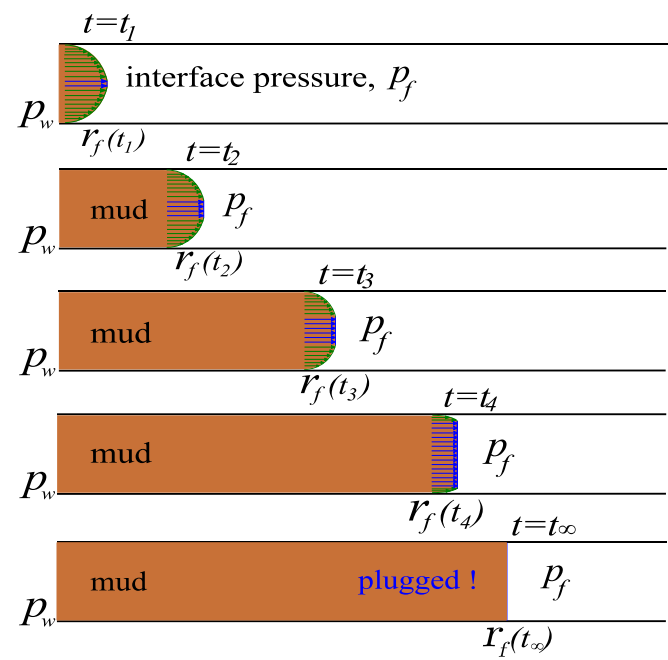

a)

Fig. 3 Illustration (a) of yield-power-law fluid flow in a radial fracture showing the evolution of the propagation of the plug region as the mud travels away from the wellbore, resulting in total plugging. Plot (b) shows

$v_{r}(z)\left\{\begin{array}{cc}v_{r, p l u g}(z), & \text { for } z \leq z_{\text {plug }} \\ v_{r, \text { free }}(z), & \text { for } z_{\text {plug }}<z<\frac{w}{2} \\ 0, & \text { for } z=\frac{w}{2}\end{array}\right.$

In Eq. (5), $z_{p l u g}$ is the vertical extension of the plug region. $v_{r, \text { plug }}$ and $v_{r}$, free denote the velocities within the plug region and free region, respectively. The last condition is a result of no-slip B.C.

A detailed description of the solution method is provided in Appendix 1. Here, we only show the key derivations. Combining Eqs. (3) and (4), and solving the differential equation of velocity in the $Z$-direction, we get,

$v_{r}(z)=\frac{n\left(-\frac{\partial p}{\partial r} \frac{w}{2}+\tau_{0}\right)\left(\frac{\frac{\partial p p_{w}}{\partial r-2} \tau_{0}}{m}\right)^{1 / n}+n\left(-\frac{\partial p}{\partial r} z+\tau_{0}\right)\left(\frac{\frac{\partial p_{p} z-\tau_{0}}{m}}{m}\right)^{\frac{1}{n}}}{\frac{\partial p}{\partial r}(n+1)}$

In the plug region, $d v_{r} / d z=0$, therefore, writing Eq. (6) for each region separately, one gets,

$$
\begin{gathered}
v_{r, f r e e}(z)=\frac{n}{n+1}\left(z_{\text {plug }}-\frac{w}{2}\right)\left(\frac{\frac{\partial p}{\partial r}\left(\frac{w}{2}-z_{\text {plug }}\right)}{m}\right)^{1 / n}+\frac{n}{n+1} \\
\left(z-z_{\text {plug }}\right)\left(\frac{\frac{\partial p}{\partial r}\left(z-z_{\text {plug }}\right)}{m}\right)^{\frac{1}{n}} \\
v_{r, \text { plug }}(z)=\frac{n}{n+1}\left(\frac{\tau_{0}}{\frac{\partial p}{\partial r}}-\frac{w}{2}\right)\left(\frac{\left(\frac{w}{2} \frac{\partial p}{\partial r}-\tau_{0}\right)}{m}\right)^{1 / n}
\end{gathered}
$$

The total volumetric flow rate $Q_{\text {total }}$ is written as the sum of the rate within the plug region $Q_{p l u g}$, and within the free region

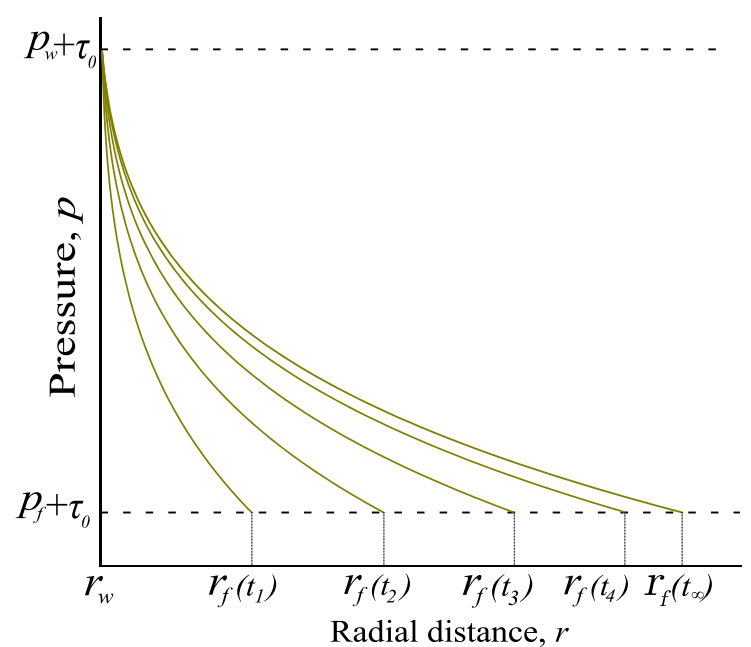

b)

typical pressure profiles versus radial distance at various times and invasion distances, where a constant injection pressure is assumed at the wellbore

$Q_{\text {free }}$, that is,

$Q_{\text {total }}=Q_{\text {plug }}+Q_{\text {free }}$

On the other hand, the flux can be expressed in terms of the surface integral for each region by:

$Q_{\text {total }}=4 \pi r \int_{0}^{z_{\text {phug }}} v_{r, p h g} d z+4 \pi r \int_{z \text { plug }}^{w / 2} v_{r, f r e e} d z$

Substituting Eq. (7) in Eq. (9) and integrating along the fracture aperture, we get,

$$
\begin{aligned}
Q_{\text {total }}^{n}=\frac{(4 \pi r)^{n}}{m} & \left(\frac{w}{2}\right)^{2 n+1}\left(\frac{n}{2 n+1}\right)^{n}\left(\frac{d p}{d r}\right)\left(1-\frac{\tau_{0}}{\frac{w}{2} \frac{d p}{d r}}\right)^{n} \\
& \left(1-\left(\frac{1}{n+1}\right) \frac{\tau_{0}}{\frac{w}{2} \frac{d p}{d r}}-\left(\frac{n}{n+1}\right)\left(\frac{\tau_{0}}{\frac{w}{2} \frac{d p}{d r}}\right)^{2}\right)^{n}
\end{aligned}
$$

By rearranging Eq. (10), it can be simplified to an ODE with a quadratic form, as follows,

$$
\left(\frac{d p}{d r}\right)^{2}-\left(\frac{Q_{\text {total }}^{n}}{r^{n} A}+B\right) \frac{d p}{d r}+D=0
$$

where the quantities $A, B$ and $D$ are nonlinear functions of $n$, $m$, and $w$, as discussed in Appendix 1.

By solving for the quadratic Eq. (11) analytically and selecting the positive physical root, we get,

$\frac{d p}{d r}=\frac{1}{2}\left(B+\frac{Q_{\text {total }}^{n}}{r^{n} A}+\sqrt{\left(B+\frac{Q_{\text {total }}^{n}}{r^{n} A}\right)^{2}-4 D}\right)$ 
Finally, by integrating Eq. (12) and recalling the total flux, we reach the final ODE system to solve:

$$
\left\{\begin{array}{c}
p_{f}-p_{w}=\frac{B\left(r_{f}(t)-r_{w}\right)}{2}+\frac{Q_{\text {total }}^{n}\left(r_{f}(t)^{1-n}-r_{w}^{1-n}\right)}{2(1-n) A}+\frac{1}{2} \int_{r_{w}}^{r_{f}(r)}\left(\sqrt{\left(B+\frac{Q_{\text {total }}^{n}}{r^{n} A}\right)^{2}-4 D}\right) d r \\
Q_{\text {total }}=2 \pi w r_{f}(t) \frac{d r_{f}(t)}{d t}
\end{array}\right.
$$

The ODE system in Eq. (13) is nonlinear and cannot be solved analytically, except for a particular case when $n=1$ (see Appendix 2). Therefore, a numerical ODE solver is used to solve Eq. (13) starting with initial conditions $r_{f}(t=0)=r_{w}$ (see Appendix 1). Note that Eq. (13) shows only the difference between the inlet pressure and the pressure in the fracture $\left(p_{f}\right.$ $-p_{w}$ ) is needed to be modeled.

\section{Model verification: particular analytical solution}

Our proposed semi-analytical solution is a generalization of the one introduced by Liétard et al. (2002) for Bingham plastic fluids. By taking a unity flow index $(n=1)$ in Eq. (4), the Herschel-Bulkley model reduces to the Bingham plastic model such that,

$\tau(z, r)=\tau_{0}+m \frac{d v_{r}}{d z}$

In Appendix 2, we show the derivation of a particular case of the proposed solution when $n=1$. Figure 4 compares the solutions of the mud invasion front (dimensionless) versus a dimensionless time obtained by our model and the one

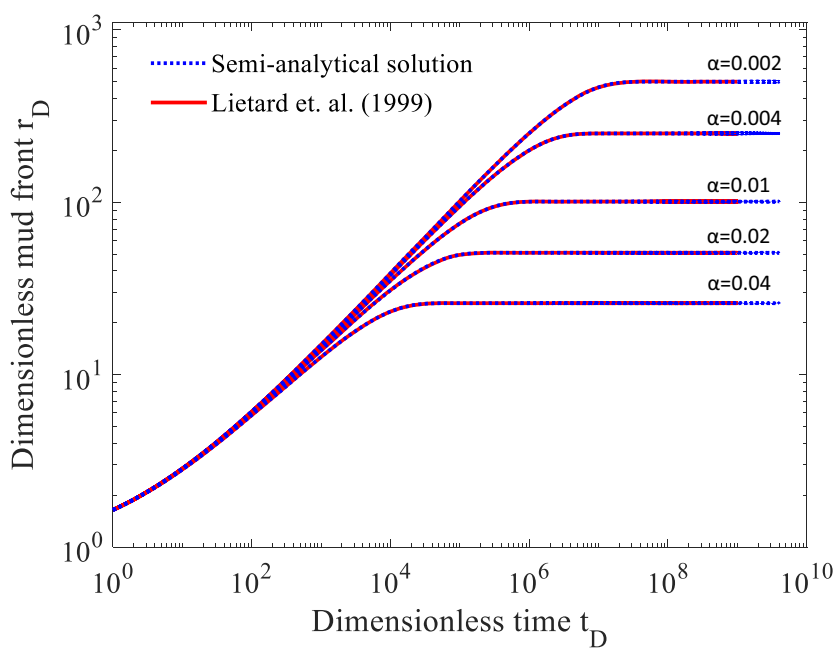

Fig. 4 Comparisons of solutions from a particular case of the proposed semi-analytical with the analytical solution by Liétard et al. (2002) for Bingham plastic fluid model. The corresponding type curves show the invasion front versus time, generated for different values of alpha between 0.002 and 0.04 proposed by Liétard et al. (2002), which shows identical match. The solutions are presented for various values between 0.002 and 0.04 of the dimensionless parameter $\alpha$, which is defined by,

$\alpha=\frac{3 r_{w}}{w}\left(\frac{\tau_{0}}{p_{f}-p_{w}}\right)$

This test case shows that a particular solution $(n=1)$ of the proposed semi-analytical model converges to the analytical solution of Liétard et al. (2002) for Bingham plastic fluids.

\section{Model verification: general solution}

We use simulations to verify our semi-analytical solutions for general Herschel-Bulkley fluids with different flow indexes, $n$. Simulations were performed using a finite-element method within COMSOL-Multiphysics (Littmarck and Saeidi 1986) to solve the flow of a non-Newtonian fluid within two parallel circular plates, mimicking the geometry of the radial fracture, shown in Fig. 1. We emphasize that the numerical solution is based on the Navier-Stokes equations, whereas the semianalytical solution is based on the more general Cauchy equation of motion corresponding to the Herschel-Bulkley fluid. To address the discrepancy between the two solution methods, we use the approach by Papanastasiou (1987), which links the Navier-Stokes equation with the Cauchy equation by manipulating the Herschel-Bulkley fluid as,

$\boldsymbol{\mu}_{e f f}(\gamma)=\boldsymbol{\mu}_{0}\left(1-e^{-m_{p} \gamma}\right)+m(\dot{\gamma})^{n-1}$

where the effective viscosity as a function of shear rate $\boldsymbol{\mu}_{\text {eff }}$ $(\dot{\gamma})$ is written in terms of the viscosity due to yield stress $\boldsymbol{\mu}_{0}$, consistency multiplier $m$, shear rate $\dot{\gamma}$, behavioral flow index $n$, and a regularization exponent $m_{p}$. The parameter $m_{p}$ has no physical significance. However, it is important to avoid singularities in the numerical solutions. Based on a sensitivity study (not shown here) to assess the effect of $m_{p}$, we found that $m_{p}=100$ to 500 provided reasonable accuracy and 
robustness. High-resolution simulations were also needed to reduce instabilities and numerical artifacts. The accuracy of this numerical solution has been discussed previously (Albattat and Hoteit 2019).

In the simulation model, the fracture is assumed to be initially saturated in water at a constant pressure. The size of the fracture in the simulation domain is selected to be large enough to mimic infinite boundary conditions. The simulation solution includes the pressure solution in the mud and water zones, and the mud-front propagation (Albattat and Hoteit 2019). Figure 5 compares the semi-analytical solutions and the numerical solutions obtained for two cases with $n=1$ and $n=0.7$, reflecting a yield stress shear-thinning fluid. The solutions describe the mud invasion distance versus time. The plateau section in the curves reflects the maximum invasion distance that is when the mud front stalls. Both solution methods are in good agreement.

\section{Type curves}

Type curves are often generated with dimensionless groups to provide quick interpretations and diagnostics of timedependent trends. This technique is commonly used in well testing (Lee 1982). In this work, we adopt the following dimensionless variables:

$$
\begin{gathered}
r_{D}=\frac{r_{f}}{r_{w}} \\
V_{D}=\frac{V_{m}}{V_{w}}=\frac{\pi w\left(r_{f}^{2}-r_{w}^{2}\right)}{\pi w_{w}^{2}}=\left(\frac{r_{f}}{r_{w}}\right)^{2}-1=r_{D}^{2}-1 \\
\alpha=\left(\frac{2 n+1}{n+1}\right)\left(\frac{2 r_{w}}{w}\right)\left(\frac{\tau_{0}}{\Delta p}\right) \\
\beta=\left(\frac{n}{2 n+1}\right)\left(\frac{w}{r_{w}}\right)^{1+\frac{1}{n}}\left(\frac{\Delta p}{m}\right) \frac{1}{n} \\
t_{D}=t \beta
\end{gathered}
$$

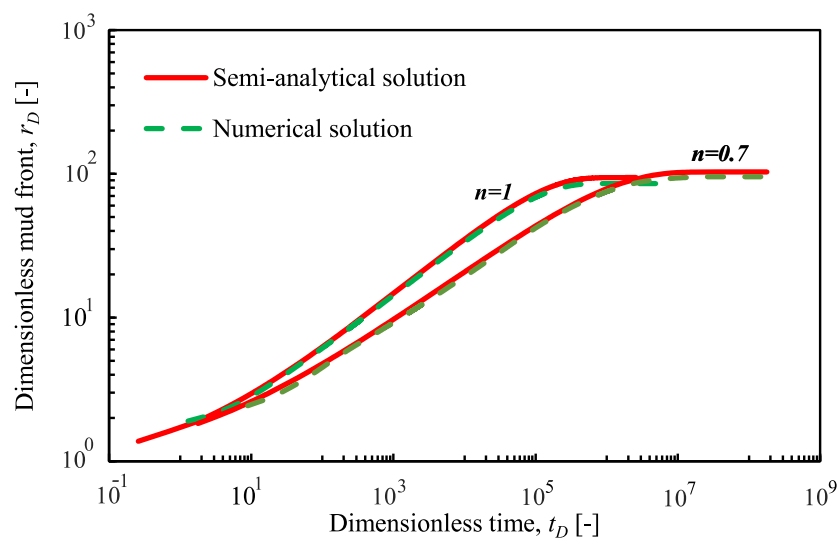

Fig. 5 Comparison between the proposed semi-analytical solutions with the numerical solutions by COMSOL. Both methods show good agreements for different cases, $n=1$ and 0.7 where $r_{D}$ is the dimensionless mud-invasion radius, $V_{D}$ is the dimensionless mud-loss volume, $t_{D}=\beta t$ is the dimensionless time, and $a$ and $\beta$ are dimensionless parameters reflecting invasion stoppage behavior and fluid rheological behavior. Additional analysis of the effect of $a$ is discussed below. The governing system of equations given in Eq. (13) is then rewritten in terms of the dimensionless variables, where the same solution method is applied. Additional details on the derivation of the dimensionless form of the semi-analytical solution are shown in Appendix 3. Figure 6 shows a set of type curves generated for different flow indexes $n=1.0,0.8$, 0.6 , and 0.4 and different values of $a$. The type curves show cumulative mud loss increase versus time. At far enough distance from the wellbore, the plugging effect becomes more significant and the fluid eventually halts.

We compare our derived type curves with the one proposed by Majidi et al. (2010). Majidi et al.'s model simplifies a nonlinear term in the governing equation by a linear term corresponding to a first-order Taylor's expansion. With this simplification, Majidi et al. (2010) could generate an approximate analytical solution. In this work, however, we kept a second nonlinear order in the equations. As a result, it was not possible to generate a full analytical solution, but rather a semi-analytical solution, as detailed in Appendix 1.

We found that the accuracy of this simplified solution by Majidi et al. (2010) depends on the selected problem parameters. Figure 7 shows a comparison between the solutions of Majidi et al. and the proposed solutions for different values of $a$. The flow indexes are, respectively, $n=0.6$ and 0.4 , from left to right. At high values of $a$, both solutions are consistent. However, as $a$ decreases, the approximation error in Majidi et al.'s (2010) solution increases, as depicted in Fig. 8. The error reduces when the flow index increases or approaches unity.

\section{Method demonstration}

The proposed semi-analytical method is applied to four wells from two different fields. In field case 1, the drilling mud was Bingham plastic fluid with known fluid properties. A deterministic approach is used to match the data with the semianalytical model. In field case 2, a more complex HerschelBulkley fluid was used. In this case, a probabilistic approach is adopted to account for various uncertainties in the mud and subsurface formation properties. Alterations in the mud properties could occur for various reasons such as mud/water in situ mixing and transient thermal effects.

\section{Field case 1}

In the first case, a drilling Bingham plastic fluid was used for the drilling of two wells: Machar 18 and Machar 20, in the Machar field in the North Sea (Liétard et al. 2002). Lost 

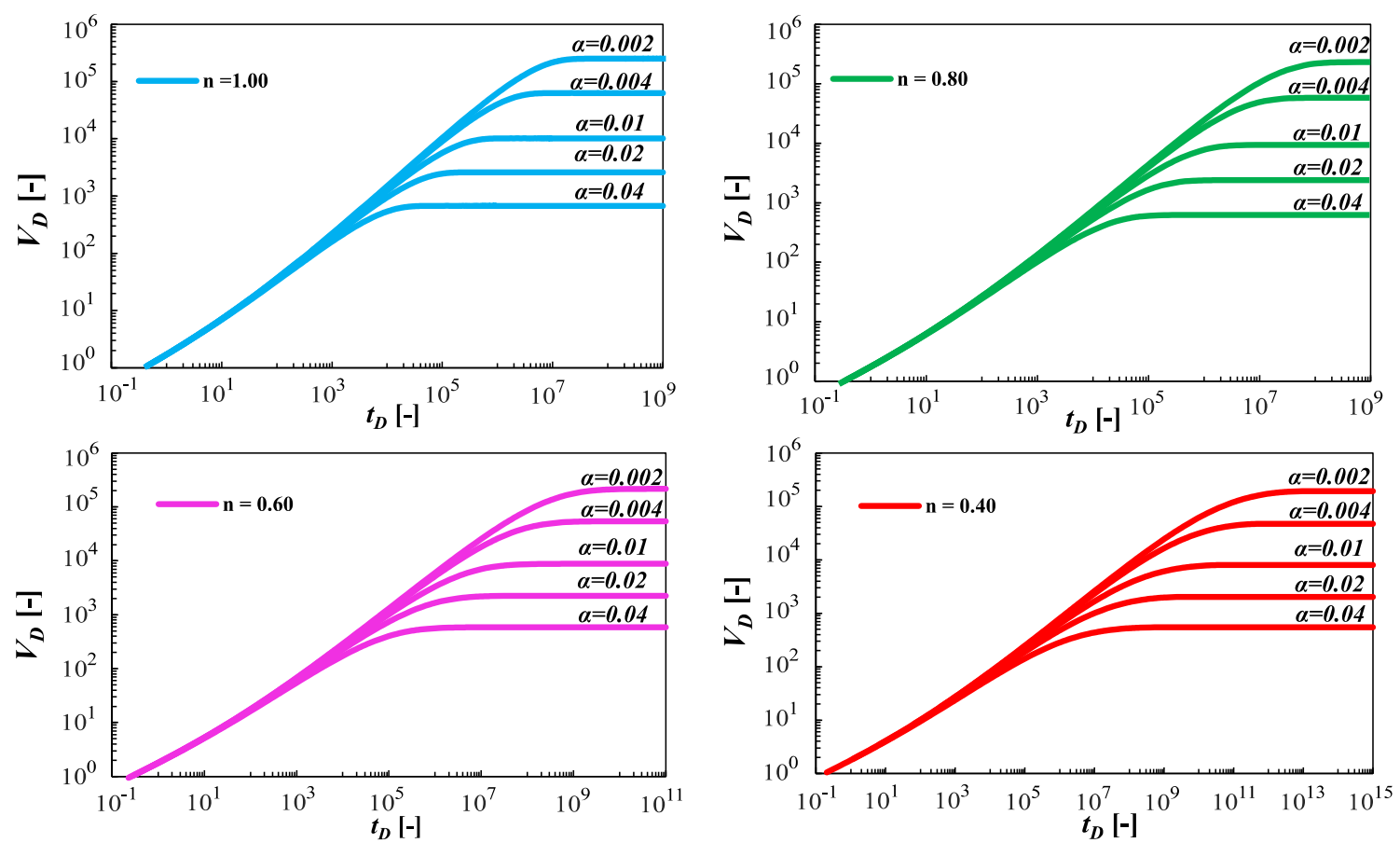

Fig. 6 Type curves in a dimensionless form showing dimensionless mud-loss volume $\left(V_{D}\right)$ versus dimensionless time $\left(t_{D}\right)$ for different values of $n(n=1$, $0.8,0.6$, and 0.4$)$ and $a(a=0.002,0.004,0.01,0.02$, and 0.04$)$

circulations within naturally fractured formation were encountered in both wells, as shown in Fig. 9. The fracture apertures were estimated to be around 0.42 and $0.64 \mathrm{~mm}$ for Machar 18 and Machar 20, respectively, based on a simplified method proposed by Huang et al. (2011). The limitation of Huang et al.'s (2011) method is in the assumption that the total mud-loss volume must be known, which is available in this case. In our proposed approach, however, the total mud-loss volume can be predicted by fitting the transient mud-loss behavior versus dimensionless time.

We note that the well data, given in Fig. 9, as provided by Liétard et al. (2002), are plotted versus different

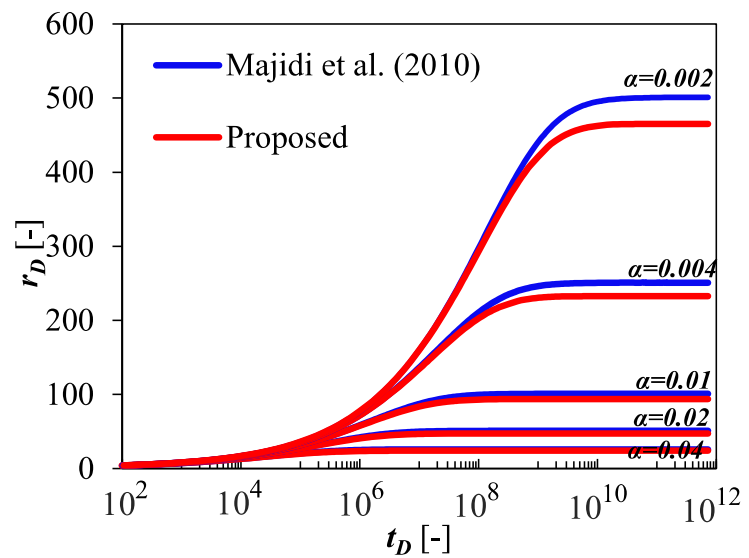

a)

Fig. 7 Comparisons of the dimensionless mud-front radius $\left(r_{D}\right)$ versus dimensionless time $\left(t_{D}\right)$ obtained by the simplified solutions of Majidi et al. (2010) and our proposed method. Different cases are considered, dimensionless groups than the ones used here. For consistency, we replotted these field data using the proposed dimensionless variables given in Eq. (17), as shown in Fig. 10. The semi-analytical solutions were then generated to replicate the transient mud-flow, which produced an excellent match to the trends, as depicted in Fig. 10. In this case, the behavioral flow index is unity $(n=1)$ for Bingham plastic fluid model, $19.5 \mathrm{lb} . / 100 \mathrm{ft}^{2}$ of yield value, and $35 \mathrm{cp}$ of plastic viscosity. The dimensionless parameters are $\alpha=0.00215$ and 0.0006436 , respectively. Fracture apertures of Machar 18 and Machar 20 wells were found to be $w=0.425 \mathrm{~mm}$ and $0.616 \mathrm{~mm}$.

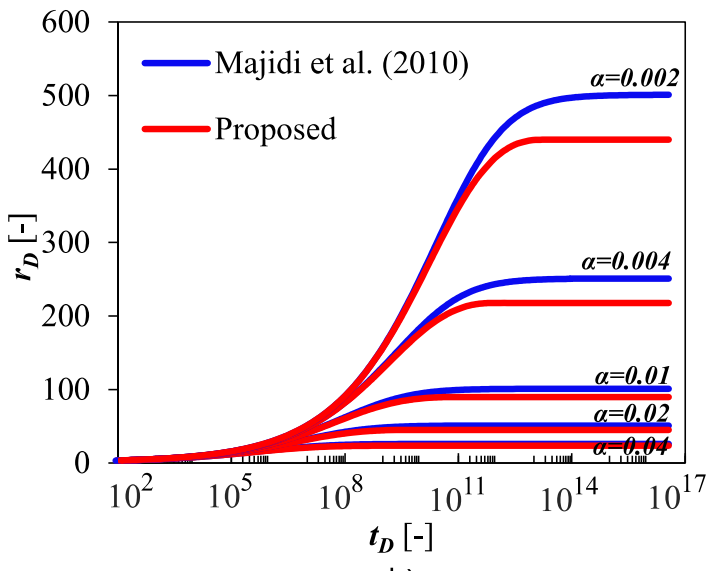

b)

corresponding to flow indexes $n=0.60$ (a) and $n=0.40$ (b). The simplified solution becomes less accurate as $\alpha$ decreases 


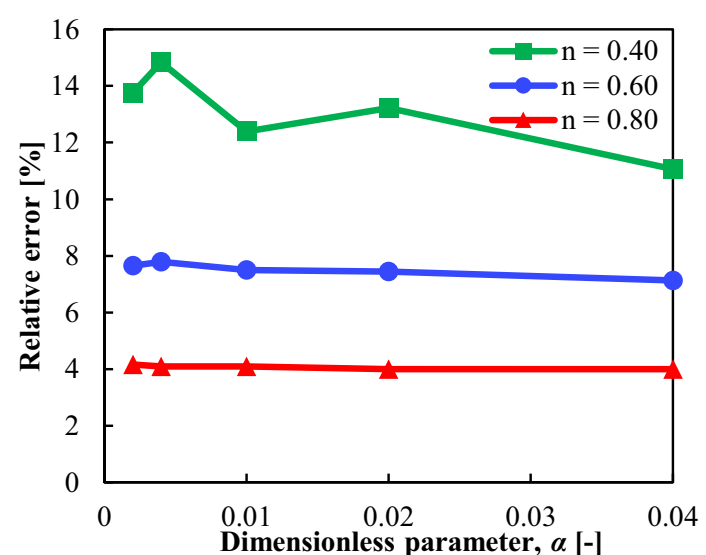

a)

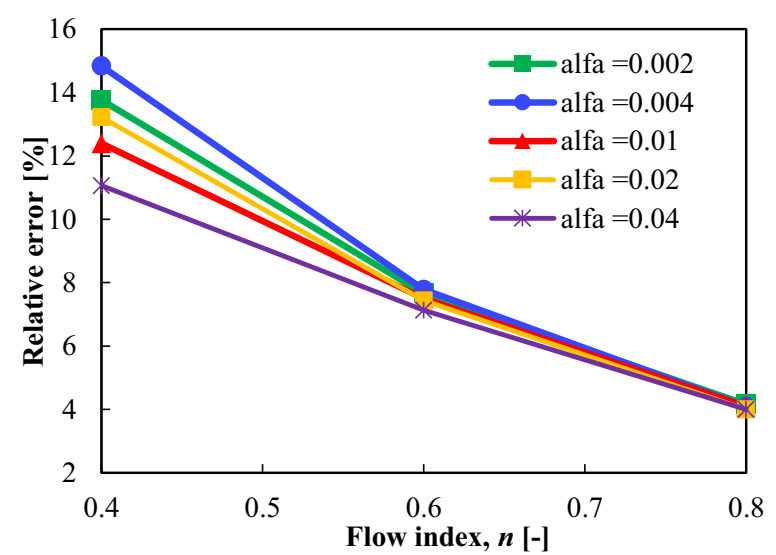

b)

Fig. 8 Plots showing the behavior of the deviation error in Majidi et al. (2010) solutions as a function of $n$ (a) and $\alpha$ (b)

\section{Field case 2}

The second field case corresponds to two wells in the Gulf of Mexico (Majidi 2008; Majidi et al. 2010). The mud-loss volumes (gallons per minute) were reported versus time in the two zones for a limited period before the mud-loss stops, as shown in Fig. 11. The pressure drop, which is the difference between the injection pressure and initial formation pressure, was reported to be within the range of 700-800 psi, and mud properties are $n=0.94, \mathrm{~m}=0.08 \mathrm{lbf} / 100 \mathrm{ft}^{2}$, and $\tau_{0}=8.4 \mathrm{lbf} /$ $100 \mathrm{ft}^{2}$ at surface conditions.

Because of the nature of uncertainties in the drilling fluid and subsurface properties, we apply a probabilistic modeling approach using Monte Carlo simulations. This probabilistic approach is needed to account for various uncertainties in the fluid property alterations related to subsurface temperature conditions and fluid mixing (Babu 1998; Rommetveit and Bjorkevoll 1997). We perform uncertainty analysis by combining our semi-analytical solutions with Monte Carlo simulations. The whole process is computationally efficient and could be performed within seconds. We vary six input

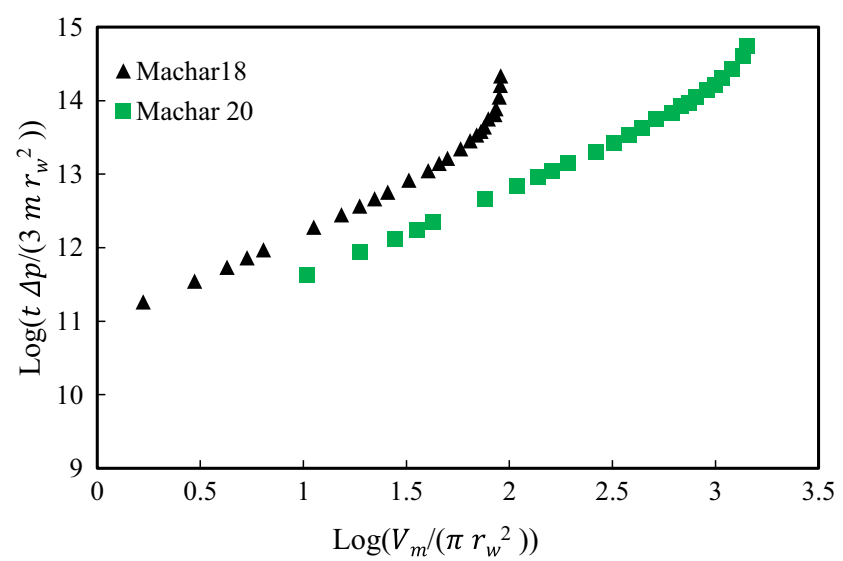

Fig. 9 Cumulative mud losses encountered in two wells in the Machar field, data acquired from Liétard et al. (2002) parameters, including the flow index, yield stress, fracture aperture, consistency factor, and pressure drop.

Figure 12 (right) corresponds to the parameters in zone 2. These distributions are used as inputs for the semi-analytical model, which is driven by the Monte Carlo simulation process. The history match corresponds to the time-dependent cumulative mud-loss volume, where uncertainties are taken into consideration. Figure 13 (left) shows the solution matching band of the field data using the semi-analytical solution combined with Monte Carlo simulations. The matching p10, p50, and p90 percentiles are also shown. Figure 13 (right) uses a violin plot to highlight the distribution behavior of the solution versus time. Figure 14 shows similar analyses done to match the data in zone 2 .

For well 1, the obtained probabilistic predictions for the fracture aperture were $0.57,0.79$, and $1.01 \mathrm{~mm}$ for $\mathrm{p} 10, \mathrm{p} 50$, and $\mathrm{p} 90$, respectively. The predicted total mud-loss volumes were 968, 2591, and 5331 bbl for p10, p50, and p90,

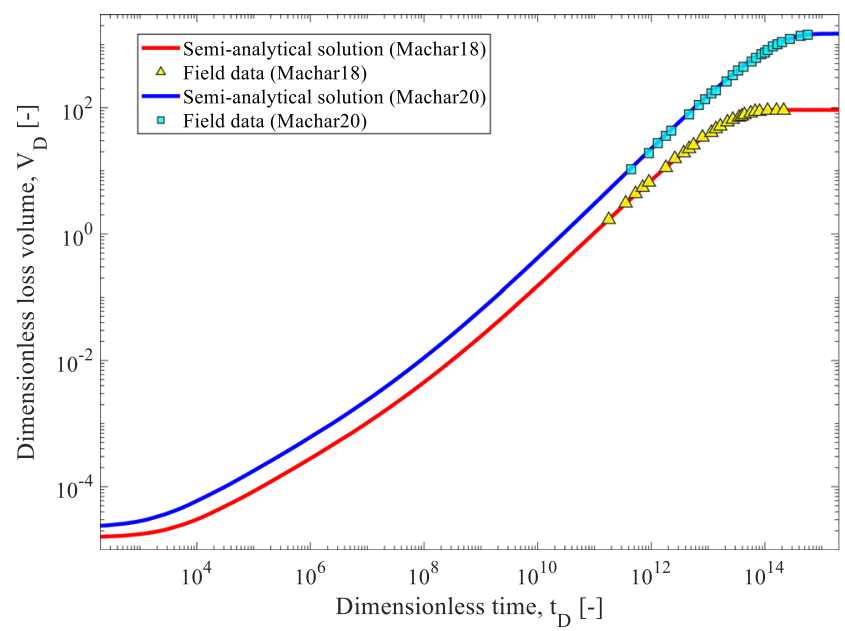

Fig. 10 Matching solutions for the two field data sets of Machar field using dimensionless variables. Both graphs' data were processed to capture transient leakage behavior. The upper graph is for Machar20, and the lower plot is for Machar18 


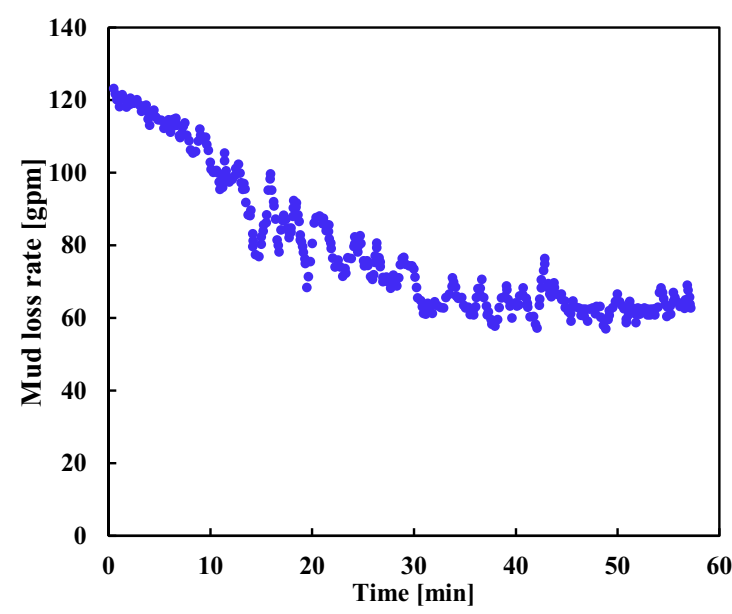

a)

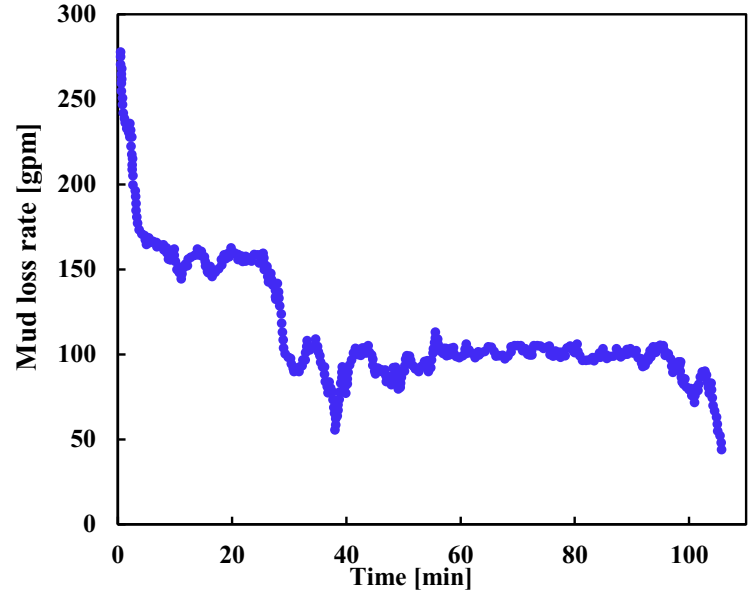

b)

Fig. 11 Mud-loss volume rate (gallons per minute) versus time (minutes) reported for two wells, 1 and 2, in the Gulf of Mexico (Majidi 2008 ). a Well 1. b Well 2

respectively. The probabilistic distributions of the matching parameters are shown in Fig. 15 for well 1, and in Fig. 16 for well 2.

\section{Discussion}

The objective of the proposed model is to develop a numerical diagnostic tool to help predict the dynamic behavior of mud leakage into fractured formation. The tool can be used to perform quick sensitivity analyses and what-if scenarios to optimize LCM selection. The model is based on simple computations and runs efficiently in a spreadsheet. This feature makes it convenient to be coupled with Monte Carlo simulations to address uncertainties, where thousands of simulations are typically needed. The input data for the model corresponds to the drilling fluid rheological properties, the injection pressure drop, and the mud-flow rate. The modeling procedure consists of (1) converting and plotting the cumulative mud volumes versus a dimensionless time and (2) matching the trend with the semi-analytical model or the type curves by tuning the fracture hydraulic aperture. As a result, the matching trend provides an estimate of the fracture hydraulic aperture and a prediction of the mud-loss behavior, including the flow halt time and the total ultimate volume of mud leakage.
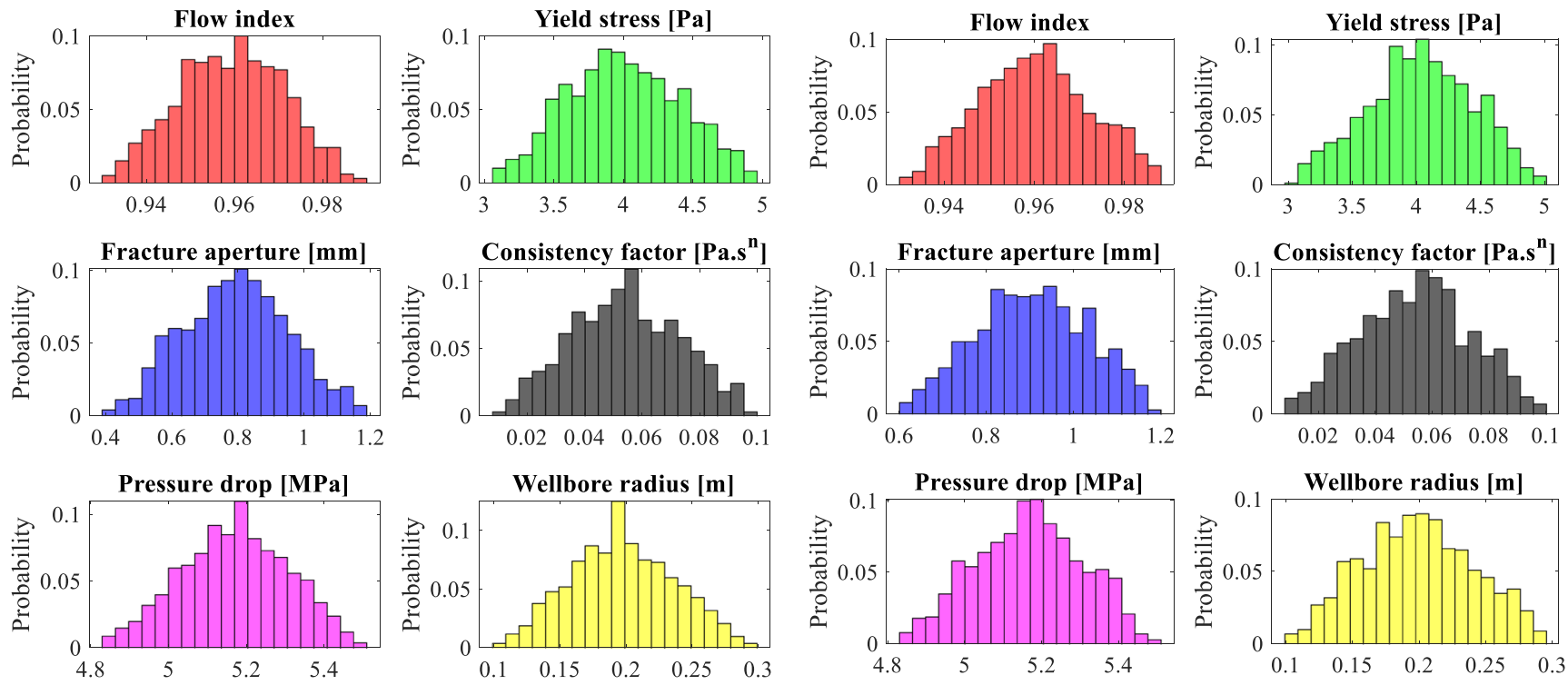

a)

b)

Fig. 12 Histograms showing the distributions of the input parameters, modified from Reza Majidi (2008), used in the Monte Carlo simulations for zone 1 (a) and zone 2 (b) 


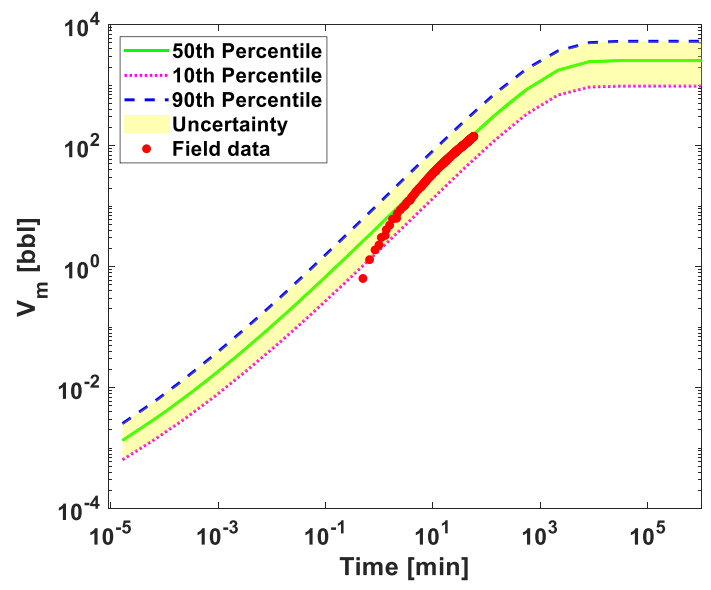

a)

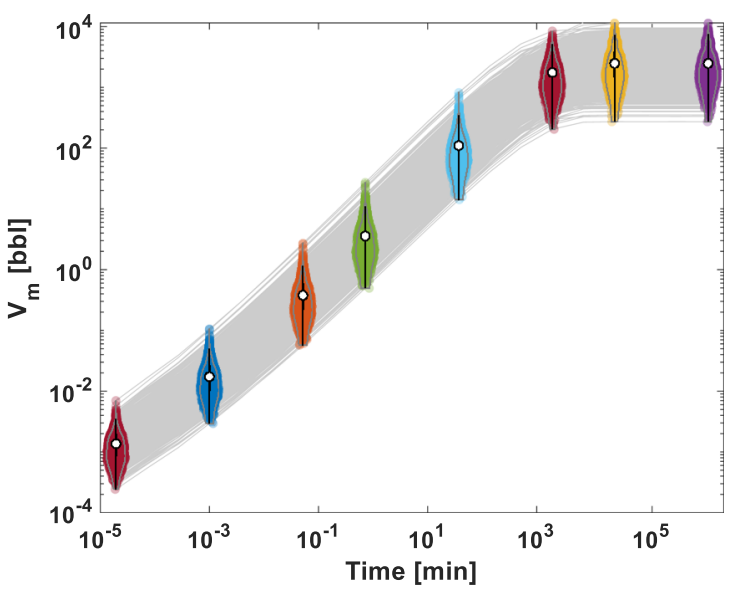

b)

Fig. 13 Well 1 data and corresponding solution match of cumulative mud-loss volume $\left(V_{m}\right)$ versus time, showing the p10, p50, and p90 percentiles (a) and with the solution distribution behavior (b). a Model match with uncertainty range. b Distribution of probabilistic match

The presented model assumes laminar flow, which may not be valid in the case of turbulent flow. Turbulent flow, however, is known to occur in the near-wellbore region for gas wells operating at high production or injection rates, and is less common for liquids (Morris et al. 1987; Lin et al. 2015). The fluids we are dealing with in this work are highly viscous, where the fluid flow takes place in natural fractures with an aperture within the range of millimeters. The reduced Reynold's number $(R e)$ for 1D radial flow is given by,

$\operatorname{Re}=\frac{v w^{2}}{\mu r}$,

where $r$ is the characteristic radius from the wellbore, $v$ is the average velocity at distance $r, w$ is the fracture aperture, and $\mu$ is the fluid viscosity. For instance, with $\mu=100 \mathrm{cp}, w=1 \mathrm{~mm}$, and flow loss rate into the fracture at $1 \mathrm{gal} / \mathrm{s}$, which is substantially high. The reduced Reynolds number at $r=10 \mathrm{~cm}$ will be
$R e=\sim 0.6<1$, which is still within the laminar flow regime (Majidi 2008).

It should be noted that the proposed model is based on several simplifications, and therefore, its applicability is conditional. The main simplifications include the assumption of mud flow in a horizontal fracture. This assumption was adopted to neglect the buoyancy effect, driven by the difference of densities of the drilling mud and the in situ water. Consequently, the model is not expected to be applicable when the gravity effect is significant such as in the case of mud with a specific gravity different from one, flowing in inclined fractures. The model also neglects the effect of water displacement, downstream of the mud. Therefore, the pressure of the water phase is assumed constant, equal to the initial pressure of the formation. This assumption is valid when the mud viscosity is significantly higher than the water viscosity. Note that an analogy to this assumption is in Richards

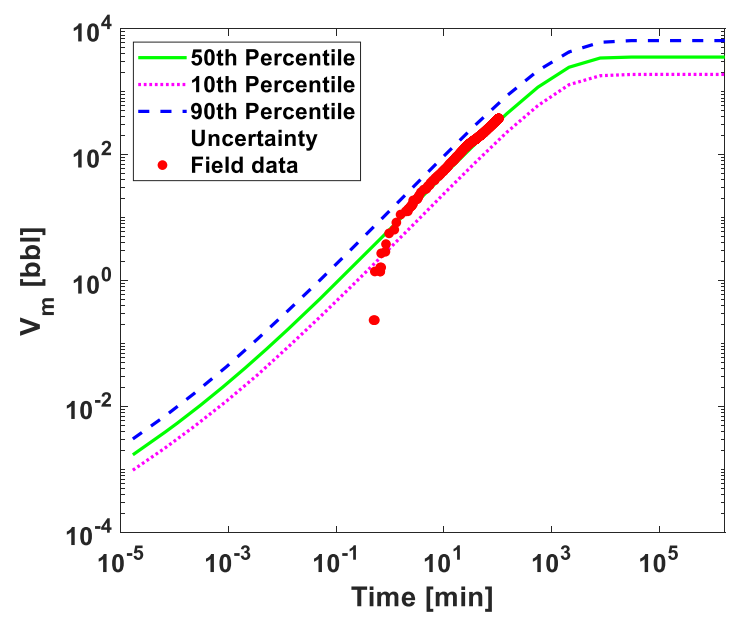

a)

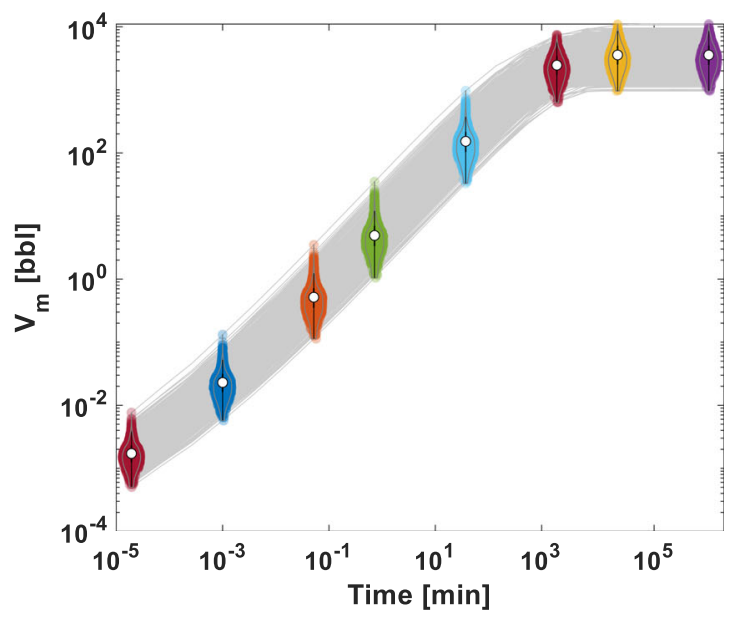

b)

Fig. 14 Well 2 data and corresponding solution match of cumulative mud-loss volume versus time, showing the p10, p50, and p90 percentiles (a) and with the solution distribution behavior (b). a Model match with uncertainty range. b Distribution of probabilistic match 


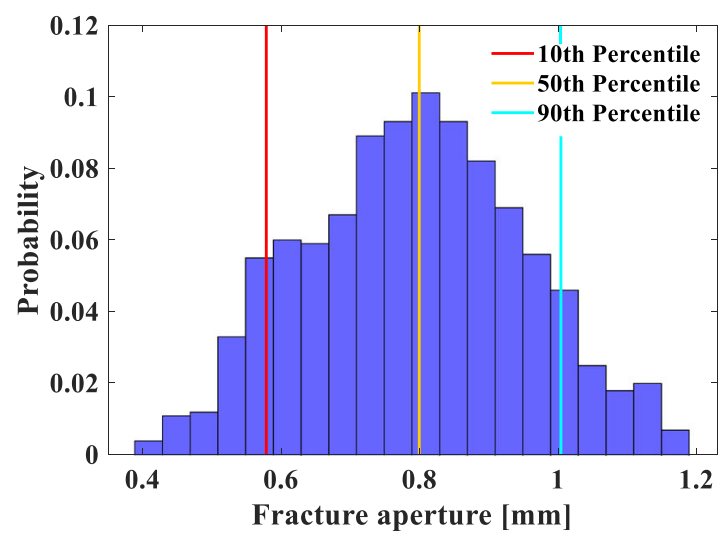

a)

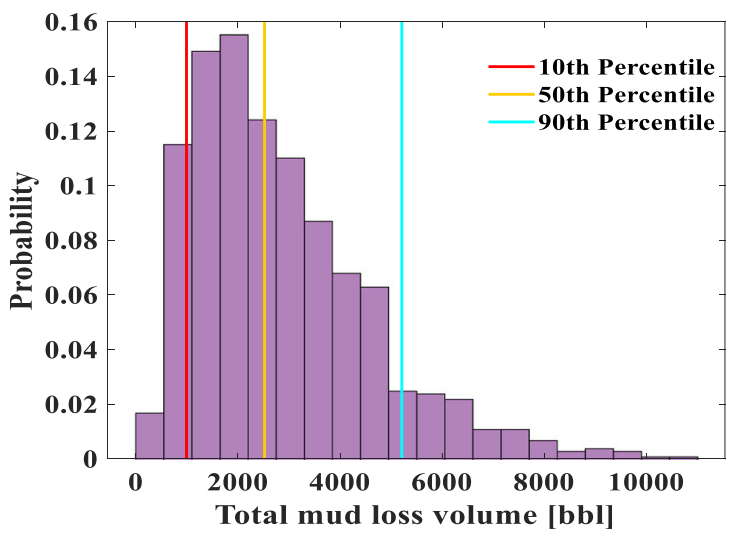

b)

Fig. 15 Histograms showing the predicted probabilistic distribution of the fracture aperture (a) and the total mud-loss volume (b) for zone 1. a Distribution of fracture aperture uncertainty, $\mathbf{b}$ Distribution of total mud loss uncertainty

equations for water flow in unsaturated porous media, where the air pressure is assumed constant. Other simplifications in our model include ignoring the mud/water in situ mixing and thermal effects. Furthermore, the modeling procedure may produce non-unique solutions. This problem is common in all curve-fitting approaches, such as pressure transient analysis (PTA) and decline curve analysis (DCA), which mostly occur if the trend of field data is not well established. Therefore, uncertainty analysis should always be accounted for, and different methods should be used to confirm the results. The use of Monte Carlo simulations may mask some physical effects that are not considered in the model. This approach could be useful to assess the range of possibilities when significant uncertainties present in the input data.

\section{Conclusions}

Lost circulation during drilling operations is a common problem that requires immediate intervention to circumvent fluid loss. Diagnostic tools, based on simplified input data such as fluid properties, pressure, and rate trends, can be quickly deployed to quantify uncertainties related to the fluid leakage into the subsurface formation and to perform predictions. In this work, a new semi-analytical approach is presented to model the leakage behavior of general Herschel-Bulkley fluids into a horizontal infinite-acting fracture, mimicking the effect of a fractured formation. The analytical approach is based on simplified assumptions such as horizontal fractures with uniform aperture. However, the proposed solution is a generalization of other analytical solutions developed for Bingham plastic fluids. The model is therefore applicable to different types of nonNewtonian fluids, including yield stress shear-thinning and shear-thickening fluids. The model verification was established for general cases using high-resolution finite element simulations. The modeling approach can adequately predict the trend of mud leakage in a system with horizontal fractures as a function of time. It can predict the effective hydraulic aperture of the fracture, the ultimate total mud-loss volume, and the expected duration before the leakage stalls, if conditions allow. We introduced dimensionless groups and generated type curves, which can provide quick diagnostics about the leakage behavior from
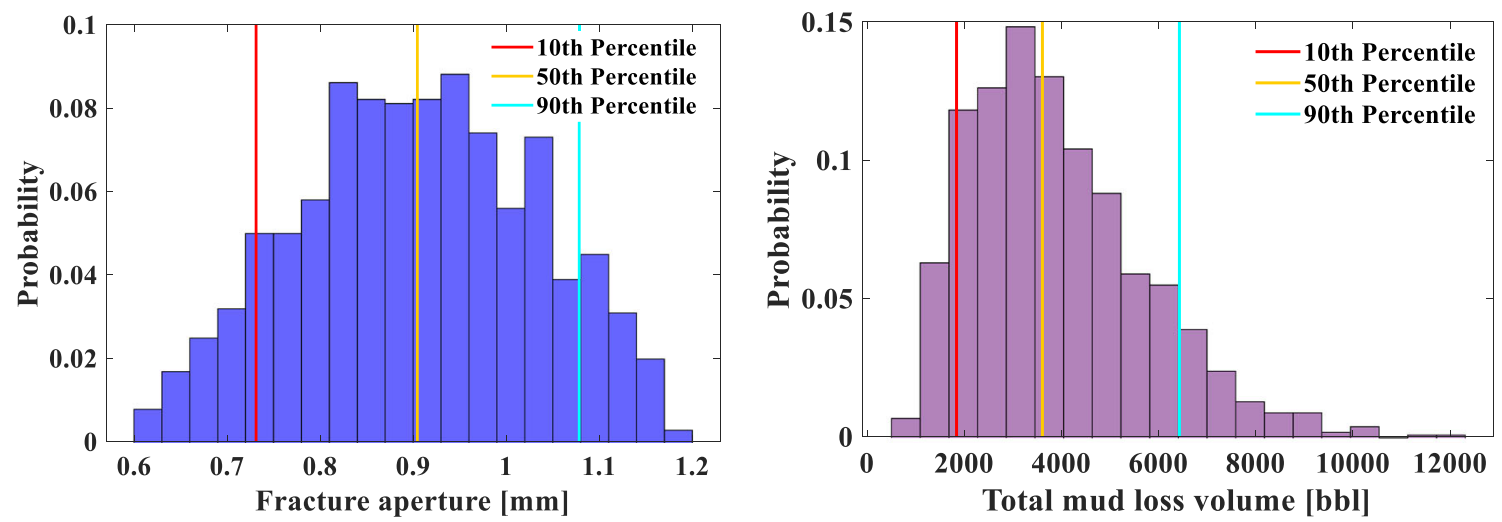

Fig. 16 Histograms showing the predicted probabilistic distribution of the fracture aperture (a) and the total mud-loss volume (b) for zone 2. a Distribution of fracture aperture uncertainty. b Distribution of total mud loss uncertainty 
matching the type curve trends without a need for simulations. We demonstrated the applicability of the model for four wells from two different fields. A numerical procedure was described to couple the model with Monte Carlo simulations to perform predictions under uncertainties. The proposed semi-analytical model is based on simple calculations that can be performed efficiently. This model is useful as a numerical diagnostic tool to perform quick predictions and to help optimize LCM selection by performing what-if scenarios.

\section{Appendix 1. Derivation from Cauchy equation to transient fluid loss}

The Cauchy equation of motion is given by:

$\rho \frac{\partial \mathbf{v}}{\partial t}+\rho(\mathbf{v} \cdot \nabla) \mathbf{v}=\nabla \cdot(-p \mathbf{I}+\boldsymbol{\tau})+\rho \mathbf{g}$

At the steady state without inertial and gravity effects, we get,

$0=\nabla(-p \mathbf{I}+\boldsymbol{\tau})$

In a radial system 1D, the above equation simplifies to, see Panton (1984):

$\tau_{r z}=z \frac{\partial p}{\partial r}$

Equation (20) relates the pressure to shear stress. Another equation to relate shear stress to velocity is given by HerschelBulkley model, such that,

$\tau_{r z}=\tau_{0}+m\left(\frac{d v_{r}}{d z}\right)^{n}$

Connecting these two Eqs. (21) and (20) as,

$z \frac{\partial p}{\partial r}=\tau_{0}+m\left(\frac{d v_{r}}{d z}\right)^{n}$

Solving the differential equation for the general solution of the velocity profile of the half fracture (i.e., $z \in[0, w / 2]$ ) domain, we get,

$v_{r}(z)=\frac{n\left(-\frac{\partial p}{\partial r} \frac{w}{2}+\tau_{0}\right)\left(\frac{\frac{\partial p_{w}}{\partial r 2}+\tau_{0}}{m}\right)^{1 / n}+n\left(-\frac{\partial p}{\partial r} z+\tau_{0}\right)\left(\frac{\frac{\partial p_{p} z-\tau_{0}}{m}}{m}\right)^{\frac{1}{n}}}{\frac{\partial p}{\partial r}(n+1)}$

Equation (23) is valid along the fracture aperture in the $Z$ direction, where two regions, according to the velocity profile, can be distinguished: plug (non-deformed) region and free (deformed) region. We can see from Herschel-Bulkley equation model that the plug region corresponds to zero derivative of the velocity in the $Z$-direction, that is, $\frac{d v_{r}}{d z}=0$. Substituting this condition in the fluid model with pressure Eq. (22), the following equation of fluid yield stress is obtained,

$z_{\text {plug }} \frac{\partial p}{\partial r}=\tau_{0}$

The velocity is defined at the three B.C. as,

$v_{r}(z)=\left\{\begin{array}{cc}v_{r, p l u g}(z) & \text { for } z \leq z_{\text {plug }} \\ v_{r, \text { free }}(z) & \text { for } z_{\text {plug }}<z<\frac{w}{2} \\ 0 & \text { for } z=\frac{w}{2}\end{array}\right.$

In Eq. (5), $z_{\text {plug }}$ is the vertical extension of the plug region; $v_{r, \text { plug }}$ and $v_{r, \text { free }}$ denote the velocities within the plug region and free region, respectively. The last condition is a result of no-slip B.C.

Substitute Eq. (24) into the solution of the general velocity profile in Eq. (23), we get,

$$
\begin{aligned}
v_{r . f r e e}(z)= & \frac{n}{n+1}\left(z_{\text {plug }}-\frac{w}{2}\right)\left(\frac{\frac{\partial p}{\partial r}\left(\frac{w}{2}-z_{\text {plug }}\right)}{m}\right)^{1 / n} \\
& +\frac{n}{n+1}\left(z-z_{\text {plug }}\right)\left(\frac{\frac{\partial p}{\partial r}\left(z-z_{\text {plug }}\right)}{m}\right)^{\frac{1}{n}}
\end{aligned}
$$

Use Eq. (26) to find velocity profile in the plug region (plug velocity) by substituting $z_{p l u g}=\frac{\tau_{0}}{\frac{\partial p}{\partial r}}$ and simplifying, we get,

$v_{r, p l u g}(z)=\frac{n}{n+1}\left(\frac{\tau_{0}}{\frac{\partial p}{\partial r}}-\frac{w}{2}\right)\left(\frac{\frac{w}{2} \frac{\partial p}{\partial r}-\tau_{0}}{m}\right)^{1 / n}$

Now, we have two velocity profiles as expressed as,

$$
\begin{aligned}
& v_{r, f i r e e}(z)= \frac{n}{n+1}\left(z_{p l u g}-\frac{w}{2}\right)\left(\frac{\frac{\partial p}{\partial r}\left(\frac{w}{2}-z_{\text {plug }}\right)}{m}\right)^{1 / n}+\frac{n}{n+1}\left(z-z_{\text {plug }}\right) \\
&\left(\frac{\frac{\partial p}{\partial r}\left(z-z_{\text {plug }}\right)}{m}\right)^{\frac{1}{n}} v_{r, p l u g}(z)=\frac{n}{n+1}\left(\frac{\tau_{0}}{\frac{\partial p}{\partial r}}-\frac{w}{2}\right)\left(\frac{\frac{w}{2} \frac{\partial p}{\partial r}-\tau_{0}}{m}\right)^{1 / n}
\end{aligned}
$$

We transform the velocities into the total volumetric flow rate (flux);

$Q_{\text {total }}=Q_{\text {plug }}+Q_{\text {free }}$

Applying the surface integral of the velocity field for the two regions, 
$Q_{\text {total }}=4 \pi r \int_{0}^{z_{\text {plug }}} v_{(r) p l u g} d z+4 \pi r \int_{z_{\text {plug }}}^{w / 2} v_{(r) f r e e} d z$

Substituting, we find the total flux,

$Q_{\text {total }}=\frac{4 \pi r}{m^{1 / n}}\left(\frac{d p}{d r}\right)^{1 / n}\left(\frac{w}{2}-\frac{\tau_{0}}{\frac{d p}{d r}}\right)^{1 / n+1}\left(\frac{n}{n+1} \frac{\tau_{0}}{\frac{d p}{d r}}+\frac{n}{2 n+1}\left(\frac{w}{2}-\frac{\tau_{0}}{\frac{d p}{d r}}\right)\right)$

Simplifying the above expresses to get,

$Q_{\text {total }}=\frac{4 \pi r}{m^{1 / n}}\left(\frac{w}{2}\right)^{1 / n+2}\left(\frac{n}{2 n+1}\right)\left(\frac{d p}{d r}\right)^{1 / n}\left(1-\frac{\tau_{0}}{\frac{w}{2} \frac{d p}{d r}}\right)^{1 / n}\left(1-\left(\frac{n}{n+1}\right) \frac{\tau_{0}}{\frac{w}{2} \frac{d p}{d r}}-\left(\frac{n}{n+1}\right)\left(\frac{\tau_{0}}{\frac{w}{2} \frac{d p}{d r}}\right)^{2}\right)$

To avoid obtaining complex number because of the nega-

tive $\frac{d p}{d r}$ inside the power term, we rewrite the equation as,

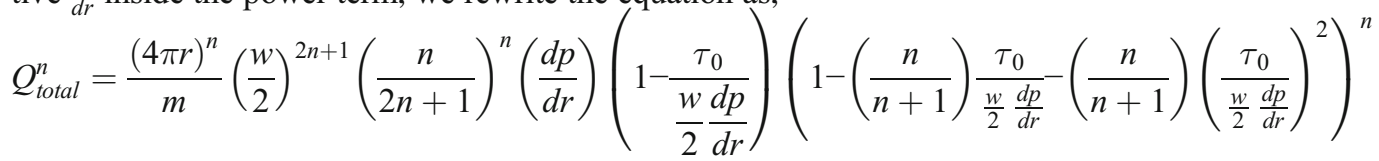

The last term is approximated by using the second-order

Taylor expansion, that is,

$Q_{\text {total }}^{n}=\frac{(4 \pi r)^{n}}{m}\left(\frac{w}{2}\right)^{2 n+1}\left(\frac{n}{2 n+1}\right)^{n}\left(\frac{d p}{d r}\right)\left(1-\frac{\tau_{0}}{\frac{w}{2} \frac{d p}{d r}}\right)\left(1-\left(\frac{n}{n+1}\right) \frac{\tau_{0}}{\frac{w}{2} \frac{d p}{d r}}-\left(\frac{n^{2}}{n+1}\right)\left(\frac{\tau_{0}}{\frac{w}{2} \frac{d p}{d r}}\right)^{2}\right)$

Simplifying,

$Q_{\text {total }}^{n}=\frac{(4 \pi r)^{n}}{m}\left(\frac{w}{2}\right)^{2 n+1}\left(\frac{n}{2 n+1}\right)^{n}\left(\frac{d p}{d r}\right)\left(1-\left(\frac{2 n+1}{n+1}\right) \frac{\tau_{0}}{\frac{w}{2} \frac{d p}{d r}}+\left(\frac{n-n^{2}}{n+1}\right)\left(\frac{\tau_{0}}{\frac{w}{2} \frac{d p}{d r}}\right)^{2}+\frac{n^{2}}{n+1}\left(\frac{\tau_{0}}{\frac{w}{2} \frac{d p}{d r}}\right)^{3}\right)$

By neglecting the higher-order terms, we get,

$Q_{\text {total }}^{n}=\frac{(4 \pi r)^{n}}{m}\left(\frac{w}{2}\right)^{2 n+1}\left(\frac{n}{2 n+1}\right)^{n}\left(\frac{d p}{d r}\right)\left(1-\left(\frac{2 n+1}{n+1}\right) \frac{\tau_{0}}{\frac{w}{2} \frac{d p}{d r}}+\left(\frac{n-n^{2}}{n+1}\right)\left(\frac{\tau_{0}}{\frac{w}{2} \frac{d p}{d r}}\right)^{2}\right)$

We arrange the pressure gradient term as a polynomial equation of second degree, that is,

$$
\begin{gathered}
0=\left(\frac{d p}{d r}\right)^{2}-\left(\frac{Q_{\text {total }}^{n}}{r^{n} \frac{(4 \pi)^{n}}{m}\left(\frac{w}{2}\right)^{2 n+1}\left(\frac{n}{2 n+1}\right)^{n}}+\left(\frac{2 n+1}{n+1}\right) \frac{\tau_{0}}{\frac{w}{2}}\right) \frac{d p_{37}}{d r} \\
+\left(\frac{n-n^{2}}{n+1}\right)\left(\frac{\tau_{0}}{\frac{w}{2}}\right)^{2}
\end{gathered}
$$

This equation can be seen as a quadratic equation with unknown $\frac{d p}{d r}$. To simplify the expression, we define the following quantities,

$$
\begin{gathered}
A=\frac{(4 \pi)^{n}}{m}\left(\frac{w}{2}\right)^{2 n+1}\left(\frac{n}{2 n+1}\right)^{n} \\
B=\left(\frac{2 n+1}{n+1}\right) \frac{\tau_{0}}{w / 2} \\
D=\left(\frac{n-n^{2}}{n+1}\right)\left(\frac{\tau_{0}}{w / 2}\right)^{2}
\end{gathered}
$$

Equation (37) becomes,

$$
0=\left(\frac{d p}{d r}\right)^{2}-\left(\frac{Q_{\text {total }}^{n}}{r^{n} A}+B\right) \frac{d p}{d r}+D
$$


This equation is a nonhomogeneous, nonlinear first-order ordinary differential equation. The general solution of the polynomial quadratic equation is in the form of $\frac{-b \pm \sqrt{b^{2}-4 a c}}{2 a}$. Hence,

$\frac{d p}{d r}=\frac{1}{2}\left(B+\frac{Q_{\text {total }}^{n}}{r^{n} A} \pm \sqrt{\left(B+\frac{Q_{\text {total }}^{n}}{r^{n} A}\right)^{2}-4 D}\right)$

There are two roots for this equation, from which the positive root is selected, thus,

$\frac{d p}{d r}=\frac{1}{2}\left(B+\frac{Q_{\text {total }}^{n}}{r^{n} A}+\sqrt{\left(B+\frac{Q_{\text {total }}^{n}}{r^{n} A}\right)^{2}-4 D}\right)$
The pressure at the inlet is $p_{w}$, and the pressure at the mudfont is $p_{f}$. It should be noted that the interface is moving with time $r_{f}(t)$. As a result, we implement a moving boundary condition at the interface only, that is,

$\int_{p_{w}}^{p_{f}} d p=\int_{r_{w}}^{r_{f}(t)} \frac{1}{2}\left(B+\frac{Q_{\text {total }}^{n}}{r^{n} A}+\sqrt{\left(B+\frac{Q_{\text {total }}^{n}}{r^{n} A}\right)^{2}-4 D}\right) d r$

Integrate the left-hand side, and the first two sides on the right-hand side, we get,

$p_{f}-p_{w}=\frac{1}{2}\left(\int_{r_{w}}^{r_{f}(t)} B d r+\int_{r_{w}}^{r_{f}(t)} \frac{Q_{\text {total }}^{n}}{r^{n} A} d r+\int_{r_{w}}^{r_{f}(t)}\left(\sqrt{\left(B+\frac{Q_{\text {total }}^{n}}{r^{n} A}\right)^{2}-4 D}\right) d r\right)$

$$
\begin{aligned}
p_{f}-p_{w}= & \frac{B\left(r_{f}-r_{w}\right)}{2}+\frac{Q_{\text {total }}^{n}\left(r_{f}^{1-n}-r_{w}^{1-n}\right)}{2(1-n) A}+\frac{1}{2} \\
& \times \int_{r_{w}}^{r_{f}(t)}\left(\sqrt{\left(B+\frac{Q_{\text {total }}^{n}}{r^{n} A}\right)^{2}-4 D}\right) d r
\end{aligned}
$$

$$
\frac{1}{2} \int_{r_{w}}^{r_{f}(t)}\left(\sqrt{\left(B+\frac{Q_{\text {total }}^{n}}{r^{n} A}\right)^{2}-4 D}\right) d r=f\left(r_{f}(t)\right)-f\left(r_{a}\right)
$$

which can be solved as (Choi et al. 2018; Vidunas 2008; Ismail and Pitman 2000),

$$
\begin{aligned}
& f\left(r_{f}(t)\right)-f\left(r_{w}\right)= \\
& F_{1}\left(\alpha, \beta, \beta^{\prime}, \gamma, \chi, \delta\right) r_{f}(t) \sqrt{\left(B+\frac{Q_{\text {total }}^{n}}{r_{f}(t)^{n} A}\right)^{2}-4 D} \\
& 2 \sqrt{\frac{B Q_{\text {total }}^{n}+A r_{f}(t)^{n}\left(B^{2}-4 D\right)-2 A \sqrt{\frac{Q_{\text {total }}^{n} D}{A^{2}}}}{r_{f}(t)^{n} A\left(B^{2}-4 D\right)}} \sqrt{\frac{B Q_{\text {total }}^{n}+A r_{f}(t)^{n}\left(B^{2}-4 D\right)-2 A \sqrt{\frac{Q_{\text {total }}^{n}}{A^{2}}}}{r_{f}(t)^{n} A\left(B^{2}-4 D\right)}}- \\
& F_{1}\left(\alpha, \beta, \beta^{\prime}, \gamma, \chi, \delta\right) r_{w} \sqrt{\left(B+\frac{Q_{\text {total }}^{n}}{r_{f}(t)^{n} A}\right)^{2}-4 D} \\
& 2 \sqrt{\frac{B Q_{\text {total }}^{n}+A r_{w}^{n}\left(B^{2}-4 D\right)-2 A \sqrt{\frac{Q_{\text {total }}^{2 n} D}{A^{2}}}}{r_{w}^{n} A\left(B^{2}-4 D\right)}} \sqrt{\frac{B Q_{\text {total }}^{n}+A r_{w}^{n}\left(B^{2}-4 D\right)+2 A \sqrt{\frac{Q_{\text {total }}^{2 n} A^{2}}{r_{w}^{n} A\left(B^{2}-4 D\right)}}}{r_{w}}}
\end{aligned}
$$

Appell's hypergeometric function of the first kind is a solution of the integral term. It is a double hypergeometric series $F_{1}\left(\alpha, \beta, \beta^{\prime}, \gamma, \chi, \delta\right)$, where,

$$
\begin{gathered}
\beta=\beta^{\prime}=-\frac{1}{2} \\
\gamma=\frac{n-1}{n} \\
\chi=-\frac{Q_{\text {total }}^{n} r^{-n}}{A B+2 A \sqrt{D}} \\
\delta=-\frac{Q_{\text {total }}^{n} r^{-n}}{A B-2 A \sqrt{D}}
\end{gathered}
$$

We substitute back these values into Eq. (46) to get, 


$$
\begin{aligned}
& f\left(r_{f}(t)\right)-f\left(r_{w}\right)= \\
& F_{1}\left(-\frac{1}{n}, \frac{1}{2}, \frac{1}{2},-\frac{1}{2}, \frac{n-1}{n}, \frac{Q_{\text {total }}^{n} r_{f}(t)^{-n}}{A B+2 \sqrt{D}}, \frac{Q_{\text {total }}^{n} r_{f}(t)^{-n}}{A B-2 \sqrt{D}}\right) r_{f} \sqrt{\left(B+\frac{Q_{\text {total }}^{n}}{r_{f}(t)^{n} A}\right)^{2}-4 D} \\
& \sqrt[2]{\left(1+\frac{B Q_{\text {total }}^{n}}{r_{f}(t)^{n} A\left(B^{2}-4 D\right)}-\frac{2 Q_{\text {total }}^{n} \sqrt{D}}{r_{f}(t)^{n} A\left(B^{2}-4 D\right)}\right)\left(1+\frac{B Q_{\text {total }}^{n}}{r_{f}(t)^{n} A\left(B^{2}-4 D\right)}+\frac{2 Q_{\text {total }}^{n} \sqrt{D}}{r_{f}(t)^{n} A\left(B^{2}-4 D\right)}\right)} \\
& F_{1}\left(-\frac{1}{n}, \frac{1}{2}, \frac{1}{2},-\frac{1}{2}, \frac{n-1}{n},-\frac{Q_{\text {total }}^{n} r_{w}^{-n}}{A B+2 \sqrt{D}}, \frac{Q_{\text {total }}^{n} r_{w}{ }^{-n}}{A B-2 \sqrt{D}}\right) r_{w} \sqrt{\left(B+\frac{Q_{\text {total }}^{n}}{r_{w}{ }^{n}}\right)^{2}-4 D} \\
& \sqrt[2]{\left(1+\frac{B Q_{\text {total }}^{n}}{r_{w}{ }^{n} A\left(B^{2}-4 D\right)}-\frac{2 Q_{\text {total }}^{n} \sqrt{D}}{r_{w}^{n} A\left(B^{2}-4 D\right)}\right)\left(1+\frac{B Q_{\text {total }}^{n}}{r_{w}{ }^{n} A\left(B^{2}-4 D\right)}+\frac{2 Q_{\text {total }}^{n} \sqrt{D}}{r_{w}{ }^{n} A\left(B^{2}-4 D\right)}\right)}
\end{aligned}
$$

We now have an analytical solution of pressure as a function of radial distance $r$. Equations (48), (45), and (44) are used when the total flow rate entering the fracture is known. Otherwise, if the total flow rate is unknown, we can use the total flow rate as,

$Q_{\text {total }}=\frac{d V_{m}}{d t}$

Mud-loss volume can be found for radial flow as,

$V_{m}=\pi w\left(r_{f}(t)^{2}-r_{w}^{2}\right)$

Substituting Eq. (50) into (49) and differentiating,

$Q_{\text {total }}=2 \pi w r_{f}(t) \frac{d r_{f}(t)}{d t}$

Finally, the mathematical problem of lost circulation in a smooth horizontal fracture is solved analytically. Equations (51), (48), (45), and (44) are the solution of mud-loss flow front $r_{f}(t)$ as a function of time $t$, based on the given parameters of mud rheology $\left(n, m, \tau_{0}\right)$, differential pressure $\left(p_{f}, p_{w}\right)$, and fracture aperture $(w)$.

\section{Appendix 2. Particular solution for Bingham plastic fluids}

Here, we show how the proposed solution can be derived mathematically for Bingham plastic fluids, when $n=1$. Let us take Eq. (36), after approximating the last term, by applying the same approach for Bingham plastic fluid condition $(n=1)$,

$Q_{\text {total }}=\frac{\pi r w^{3}}{6 m}\left(\frac{d p}{d r}-\frac{3 \tau_{0}}{w}\right)$

Integrating,

$\int_{p_{w}}^{p_{f}} d p=\int_{r_{w}}^{r_{r}(t)}\left(\frac{6 m Q_{\text {total }}}{\pi r w^{3}}+\frac{3 \tau_{0}}{w}\right) d r$
The above equation becomes,

$p_{f}-p_{w}=\frac{12 m r_{f}(t)}{w^{2}} \frac{d r_{f}(t)}{d t} \ln \left(\frac{r_{f}(t)}{r_{w}}\right)+\frac{3 \tau_{0}}{w}\left(r_{f}(t)-r_{w}\right)($

Rearranging,

$\frac{d r_{f}(t)}{d t}=\frac{\left(p_{f}-p_{w}\right)-\frac{3 \tau_{0}}{w}\left(r_{f}(t)-r_{w}\right)}{\frac{12 m r_{f}(t)}{w^{2}} \ln \left(\frac{r_{f}(t)}{r_{w}}\right)}$

Equation (55) is the final solution of Bingham plastic fluid model of mud invasion front $r_{f}(t)$ as a function of time $t$. The equation can be derived in different forms, which is consistent with the dimensionless form by Liétard et al. (2002). The defined dimensionless groups are,

$$
\begin{gathered}
\alpha=\frac{3 r_{w}}{w}\left(\frac{\tau_{0}}{p_{f}-p_{w}}\right) \\
\beta=\left(\frac{w}{r_{w}}\right)^{2} \frac{\left(p_{f}-p_{w}\right)}{12 m} \\
r_{D}=\frac{r_{f}}{r_{w}}, t_{D}=\beta t
\end{gathered}
$$

Implementing into Eq. (55) to generate a dimensionless differential form,

$\frac{d r_{D}(t)}{d t_{D}}=\frac{1-\alpha\left(r_{D}(t)-1\right)}{r_{D}(t) \ln \left(r_{D}(t)\right)}$

This is an ordinary differential equation that can be solved analytically by using inverse function theorem (IFT) in such a way that any function $f(x)$ is both differentiable and invertible. Assuming $y=f^{-1}(x)$ is the inverse of $f(x)$ which all $x$ satisfying $f^{\prime}\left(f^{-1}(x)\right) \neq 0$. Thus, the derivative,

$\frac{d y}{d x}=\frac{d}{d x}\left(f^{-1}(x)\right)=\left(f^{-1}\right)^{\prime}(x) \frac{1}{f^{\prime}\left(f^{-1}(x)\right)}$ 
Equation (57) becomes,

$\frac{d t_{D}}{d r_{D}(t)}=\frac{r_{D}(t) \ln \left(r_{D}(t)\right)}{1-\alpha\left(r_{D}(t)-1\right)}$

Providing the closed-form solution after applying initial condition at $t_{D}=0$ and $r_{D}=1$, we get,

$$
\begin{aligned}
& t_{D}=-\frac{4}{\alpha}\left(1-r_{D}+\ln \left(r_{D}^{r_{D}}\right)\right)+4\left(\frac{1}{\alpha^{2}}+\frac{1}{\alpha}\right) \\
& {\left[L i_{2}\left(\frac{\alpha}{1+\alpha}\right)-L i_{2}\left(\frac{\alpha r_{D}}{1+\alpha}\right)-\ln \left(r_{D f}\right) \ln \left(1-\frac{\alpha r_{D}}{1+\alpha}\right)\right]}
\end{aligned}
$$

In the above equation, the polylogarithmic function $\mathbf{L} \mathbf{i}_{2}$ is shown as a solution of Eq. (59), which is the analytical solution of a dimensionless mud invasion front $r_{D}$ as a function of dimensionless time $t_{D}$ for Bingham plastic fluid model. Furthermore, an analytical solution was provided as well (Liétard et al. 2002).

\section{Appendix 3. Type curves}

We derive the type curves in dimensionless form. Let us recall Eq. (44)

$$
\begin{aligned}
p_{f}-p_{w}= & \frac{B\left(r_{f}-r_{w}\right)}{2}+\frac{Q_{\text {total }}^{n}\left(r_{f}^{1-n}-r_{w}^{1-n}\right)}{2(1-n) A}+\frac{1}{2} \\
& \times \int_{r_{w}}^{r_{f}(t)}\left(\sqrt{\left(B+\frac{Q_{\text {total }}^{n}}{r^{n} A}\right)^{2}-4 D}\right) d r
\end{aligned}
$$

Dividing all terms by $\Delta p=p_{f}-p_{w}$, we get,

$$
\begin{aligned}
1= & \frac{B\left(r_{f}-r_{w}\right)}{2 \Delta p}+\frac{Q_{\text {total }}^{n}\left(r_{f}^{1-n}-r_{f w}^{1-n}\right)}{2 \Delta p(1-n) A}+\frac{1}{2 \Delta p} \\
& \times \int_{r_{w}}^{r_{f}(t)}\left(\sqrt{\left(B+\frac{Q_{\text {total }}^{n}}{r^{n} A}\right)^{2}-4 D}\right) d r
\end{aligned}
$$

Substituting the defined constants as done previously in Eq. (38) and applying the dimensionless variable $r_{D}=\frac{r_{f}}{r_{w}} r_{w}$, it yields,

$$
\begin{aligned}
1= & \frac{1}{2}\left(\frac{2 n+1}{n+1}\right)\left(\frac{\tau}{\Delta p}\right)\left(\frac{2 r_{w}}{w}\right)\left(r_{D}-1\right) \\
& +2^{n}\left(r_{D}^{1-n}-1\right)\left(\left(\frac{2 n+1}{n}\right)\left(\frac{m}{\Delta p}\right)^{\frac{1}{n}}\left(\frac{r_{w}}{w}\right)^{\frac{n+1}{n}} r_{D} r_{D}{ }^{\prime}\right)^{n}
\end{aligned}
$$

The transforming of the third term to dimensionless form, we get,

$\frac{1}{2} \int_{r_{w}}^{r_{f}(t)}\left(\sqrt{\left(\frac{B}{\Delta p}+\frac{Q_{\text {total }}^{n}}{\Delta p r^{n} A}\right)^{2}-\frac{4 D}{\Delta p^{2}}}\right) d r=$

$$
\begin{aligned}
& F_{1}\left(-\frac{1}{n}, \frac{1}{2}, \frac{1}{2}, \frac{n-1}{n},-\frac{\left(\beta \frac{d r_{D}}{d t}\right)^{n}}{1+2 \sqrt{\frac{n-n^{2}}{n+1}}+2 n\left(1+\sqrt{\frac{n-n^{2}}{n+1}}\right)},-\frac{\left(\beta \frac{d r_{D}}{d t}\right)^{n}}{2 \sqrt{\frac{n-n^{2}}{n+1}}-1+2 n\left(\sqrt{\frac{n-n^{2}}{n+1}}-1\right)}\right) \alpha r_{D} \sqrt{4 n\left(n^{2}-1\right)+\left(1+2 n+\left(\beta \frac{d r_{D}}{d t}\right)^{n}\right)^{2}} \\
& \sqrt[2]{\left(1+\frac{2(2 n+1)}{\left(1+4 n^{2}+4 n^{3}\right)}\left(\beta \frac{d r_{D}}{d t}\right)^{n}+\frac{4 n\left(n^{2}-1\right)}{\left(1+3 n+4 n^{2}+n^{3}\right)^{2}}\left(\beta \frac{d r_{D}}{d t}\right)^{2 n}+\frac{(2 n+1)^{2}}{\left(1+4 n^{2}+4 n^{3}\right)^{2}}\left(\beta \frac{d r_{D}}{d t}\right)^{2 n}\right)} \\
& F_{1}\left(-\frac{1}{n}, \frac{1}{2}, \frac{1}{2}, \frac{n-1}{n},-\frac{\left(\beta r_{D} \frac{d r_{D}}{d t}\right)^{n}}{1+2 \sqrt{\frac{n-n^{2}}{n+1}}+2 n\left(1+\sqrt{\frac{n-n^{2}}{n+1}}\right)},-\frac{\left(\beta r_{D} \frac{d r_{D}}{d t}\right)^{n}}{2 \sqrt{\frac{n-n^{2}}{n+1}}-1+2 n\left(\sqrt{\frac{n-n^{2}}{n+1}}-1\right)}\right) \alpha_{D} \sqrt{4 n\left(n^{2}-1\right)+\left(1+2 n+\left(\beta_{D} r_{D} \frac{d r_{D}}{d t}\right)^{n}\right)^{2}} \\
& \sqrt[2]{\left(1+\frac{2(2 n+1)}{\left(1+4 n^{2}+4 n^{3}\right)}\left(\beta r_{D} \frac{d r_{D}}{d t}\right)^{n}+\frac{4 n\left(n^{2}-1\right)}{\left(1+3 n+4 n^{2}+n^{3}\right)^{2}}\left(\beta r_{D} \frac{d r_{D}}{d t}\right)^{2 n}+\frac{(2 n+1)^{2}}{\left(1+4 n^{2}+4 n^{3}\right)^{2}}\left(\beta r_{D} \frac{d r_{D}}{d t}\right)^{2 n}\right)}
\end{aligned}
$$


Hence, the proposed dimensionless parameters are,

$$
\begin{gathered}
r_{D}=\frac{r_{f}}{r_{w}} \\
t_{D}=\beta_{D} \\
V_{D}=\frac{V_{m}}{V_{w}}=\frac{\pi w\left(r_{f}^{2}-r_{w}^{2}\right)}{\pi w r_{w}^{2}}=\left(\frac{r_{f}}{r_{w}}\right)^{2}-1=r_{D}^{2}-1 \\
\alpha=\left(\frac{2 n+1}{n+1}\right)\left(\frac{2 r_{w}}{w}\right)\left(\frac{\tau_{0}}{\Delta p}\right)^{1+\frac{1}{n}}\left(\frac{\Delta p}{m}\right)^{\frac{1}{n}}
\end{gathered}
$$

Acknowledgements The authors thank King Abdullah University of Science and Technology (KAUST) and Ali I. Al-Naimi Petroleum Engineering Research Center (ANPERC) for supporting this work.

\section{Declarations}

Conflict of interest The authors declare no competing interests.

Open Access This article is licensed under a Creative Commons Attribution 4.0 International License, which permits use, sharing, adaptation, distribution and reproduction in any medium or format, as long as you give appropriate credit to the original author(s) and the source, provide a link to the Creative Commons licence, and indicate if changes were made. The images or other third party material in this article are included in the article's Creative Commons licence, unless indicated otherwise in a credit line to the material. If material is not included in the article's Creative Commons licence and your intended use is not permitted by statutory regulation or exceeds the permitted use, you will need to obtain permission directly from the copyright holder. To view a copy of this licence, visit http://creativecommons.org/licenses/by/4.0/.

\section{References}

Albattat R, Hoteit H (2019) Modeling yield-power-law drilling fluid loss in fractured formation. J Pet Sci Eng 182(November):106273. https://doi.org/10.1016/j.petrol.2019.106273

Al-Hameedi ATT, Alkinani HH, Dunn-Norman S, Flori RE, Hilgedick SA, Amer AS, Alsaba M (2019) Mud loss estimation using machine learning approach. Journal of Petroleum Exploration and Production Technology Springer Verlag 9:1339-1354. https://doi.org/10.1007/ s13202-018-0581-x

Ali A, Kalloo CL, Singh UB (1997) "Preventing lost circulation in severely depleted unconsolidated sandstone reservoirs." SPE Reprint Series, no 44: 103-109. https://doi.org/10.1016/0148-9062(94) 91150-9

Ambartsumyan I, Ervin VJ, Nguyen T, Yotov I (2019) A nonlinear Stokes-Biot model for the interaction of a non-Newtonian fluid with poroelastic media. ESAIM: Mathematical Modelling and Numerical Analysis 53(6):1915-1955. https://doi.org/10.1051/m2an/2019061

Arbogast T, Brunson DS (2007) A computational method for approximating a Darcy-Stokes system governing a vuggy porous medium. Comput Geosci 11(3):207-218. https://doi.org/10.1007/s10596007-9043-0

Attong DJ, Singh UB, Teixeira G (1995) Successful use of a modified MWD tool in a high-concentration LCM mud system. SPE Drill Complet 10(1):22-26. https://doi.org/10.2118/25690-PA
Babu DR (1998) Effect of P- $\rho$-T behavior of muds on loss/gain during high-temperature deep-well drilling. J Pet Sci Eng 20(1-2):49-62. https://doi.org/10.1016/S0920-4105(98)00003-5

Bannister CE, Lawson VM (1985) Role of cement fluid loss in wellbore completion. In: Proceedings - SPE Annual Technical Conference and Exhibition 1985-Septe. https://doi.org/10.2523/14433-ms

Ben-Avraham Z, Lazar M, Garfunkel Z, Reshef M, Ginzburg A, Rotstein Y, Frieslander U, Bartov Y, Shulman H (2012) Structural styles along the Dead Sea fault. In: Roberts DG, A W B T - Regional geology and tectonics. Phanerozoic Passive Margins Bally Cratonic Basins and Global Tectonic Maps (eds) Regional geology and tectonics. Elsevier, Boston, pp 616-633. https://doi.org/10. 1016/B978-0-444-56357-6.00016-0

Bruckdorfer R, Gleit A (1988) "Static fluid loss model." SPE General, 20.

Choi DS, Yun S, Choi WS (2018) An exact solution for power-law fluids in a slit microchannel with different zeta potentials under electroosmotic forces. Micromachines 9(10). https://doi.org/10.3390/ mi9100504

Cioranescu D, Girault V, Rajagopal KR (2016) Mechanics and mathematics of fluids of the differential type. In: Advances in mechanics and mathematics, vol 35. Springer. https://doi.org/10.1007/978-3319-39330-8

Dokhani V, Ma Y, Geng T, Li Z, Mengjiao Y (2020) "Transient analysis of mud loss in fractured formations." J Pet Sci Eng 195 (December): 107722. https://doi.org/10.1016/j.petrol.2020.107722

Dyke CG, Wu B, Milton-Taylor D (1995) Advances in characterizing natural-fracture permeability from mud- log data. SPE Form Eval 10(3):160-166. https://doi.org/10.2118/25022-pa

Girault V, Rivière B (2009) DG approximation of coupled Navier-Stokes and Darcy equations by Beaver-Joseph-Saffman interface condition. SIAM J Numer Anal 47(3):2052-2089. https://doi.org/10. $1137 / 070686081$

He Y, Bu X (2020) A novel enhanced deep borehole heat exchanger for building heating. Appl Therm Eng 178(September):115643. https:// doi.org/10.1016/j.applthermaleng.2020.115643

Hemphil T, Pilehvari A, Campos W (1993) Yield-power law model more accurately predicts mud rheology. Oil Gas J 91(34):45-50

Hindmarsh AC, Brown PN, Grant KE, Lee SL, Serban R, Shumaker DE, Woodward CS (2005) SUNDIALS: suite of nonlinear and differential/algebraic equation solvers. ACM Trans Math Softw 31(3):363-396. https://doi.org/10.1145/1089014.1089020

Hoteit H, Firoozabadi A (2008) An efficient numerical model for incompressible two-phase flow in fractured media. Adv Water Resour 31(6):891-905. https://doi.org/10.1016/j.advwatres.2008.02.004

Huang J, Griffiths DVV, Wong S-WW (2011) Characterizing naturalfracture permeability from mud-loss data. SPE J 16(1):111-114. https://doi.org/10.2118/139592-PA

Irgens F (2014) Rheology and non-Newtonian fluids. Springer International Publishing

Ismail MEH, Pitman J (2000) Algebraic evaluations of some Euler integrals, duplication formulae for Appell's hypergeometric function F1, and Brownian variations. Can J Math 52(5):961-981. https:// doi.org/10.4153/CJM-2000-040-3

Kelessidis VC, Maglione R, Tsamantaki C, Aspirtakis Y (2006) Optimal determination of rheological parameters for Herschel-Bulkley drilling fluids and impact on pressure drop, velocity profiles and penetration rates during drilling. J Pet Sci Eng 53(3-4):203-224. https:// doi.org/10.1016/j.petrol.2006.06.004

Kemerli M, Engin T (2020) "Numerical analysis of a monotube mixed mode magnetorheological damper by using a new rheological approach in CFD." Rheologica Acta, December, 1-19. https://doi.org/ 10.1007/s00397-020-01252-2

Knudsen K, Leon GA, Sanabria AE, Ansari A, Pino RM (2015) First application of thermal activated resin as unconventional LCM in the Middle East. Society of Petroleum Engineers - Abu Dhabi 
International Petroleum Exhibition and Conference, ADIPEC 2015: 1-8. https://doi.org/10.2118/177430-ms

Lee J (1982) Well testing. Vol. 1. Society of Petroleum Engineers. https:// store.spe.org/Well-Testing\%2D\%2DP179.aspx

Liétard O, Tessa U, Guillot DJ, Hodder MH, Faruk C, Rasmussen ML, Liétard O, Tessa U, Guillot DJ, Hodder MH (2002) Fracture width logging while drilling and drilling mud/loss-circulation-material selection guidelines in naturally fractured reservoirs. SPE Drill Complet 17(4):237-246

Lin M, Chen S, Ding W, Chen Z, Jinze X (2015) Effect of fracture geometry on well production in hydraulic-fractured tight oil reservoirs. J Can Pet Technol 54(3):183-194. https://doi.org/10.2118/ 167761-PA

Littmarck, Svante, and Farhad Saeidi. 1986. "COMSOL Multiphysics®"

Luzardo J, Oliveira EP, Derks PWJ, Vega Nascimento R, a Perez Gramatges (2015) "Reservoir-friendly LCM for wellbore strengthening." Offshore Technology Conference, 1-20

Maglione R, Marsala A (1997) Drilling mud losses: problem analysis. AGIP Internal Report

Majidi R (2008) "Modeling of drilling fluid losses in naturally fractured formations." $\mathrm{PhD}$ thesis, The University of Tulsa

Majidi R, Miska SZ, Yu M, Thompson LG, Zhang J (2010) Quantitative analysis of mud losses in naturally fractured reservoirs: the effect of rheology. SPE Drill Complet 25(4):509-517. https://doi.org/10. 2118/114130-pa

Morris CW, Campbell DA, Petty S (1987) Analysis of geothermal wells in naturally fractured formations with rate-sensitive flow. SPE Form Eval 2(4):567-572. https://doi.org/10.2118/14169-PA

Norman J (2011) “Coriolis sensors open lines to real-time data." Drilling Contractor 67 (5): 0-3

Okoro EE, Okafor IS, Sanni SE, Obomanu T, Oguntade T, Orodu OD (2020) Investigation of reservoir permeability impairment when drilling with nanotreated drill-in mud system. In: Society of Petroleum Engineers - SPE Nigeria Annual International Conference and Exhibition 2020, NAIC 2020. Society of Petroleum Engineers. https://doi.org/10.2118/203749-ms

Olsen M, Lende G, Rehman K, Haugum P, Mo J, Smaaskjar G, Næss R (2019) Innovative and established LCM cementing solutions combined to create novel LCM cementing fluid train. In: Society of Petroleum Engineers - SPE Norway One Day Seminar 2019. https://doi.org/10.2118/195622-ms

Panton RL (1984) Incompressible flow. John Wiley \& Sons

Papanastasiou TC (1987) Flows of materials with yield. J Rheol 31(5): 385-404. https://doi.org/10.1122/1.549926
Razavi O, Lee HP, Olson JE, Schultz RA (2017) Drilling mud loss in naturally fractured reservoirs: theoretical modelling and field data analysis. Proceedings - SPE Annual Technical Conference and Exhibition 0. https://doi.org/10.2118/187265-ms

Rommetveit R, Bjorkevoll KS (1997) Temperature and pressure effects on drilling fluid rheology and ECD in very deep wells. In: Proceedings of the IADC/SPE Asia Pacific Drilling Technology Conference, APDT, 297-305. Soc Pet Eng (SPE). https://doi.org/ 10.2118/39282-ms

Russian A, Riva M, Russo ER, Chiaramonte MA, Guadagnini A (2019) Stochastic inverse modeling and global sensitivity analysis to assist interpretation of drilling mud losses in fractured formations. Stoch Env Res Risk A 33(10):1681-1697. https://doi.org/10.1007/ s00477-019-01729-4

Sanfillippo F, Brignoli M, Santarelli FJ, Bezzola C (1997) Characterization of conductive fractures while drilling. SPE European Formation Damage Conference. https://doi.org/10.2118/ 38177-ms

Seyedmohammadi J (2017) The effects of drilling fluids and environment protection from pollutants using some models. Modeling Earth Systems and Environment 3(1):23. https://doi.org/10.1007/s40808017-0299-7

Shao Q, Bouhala L, Fiorelli D, Fahs M, Younes A, Núñez P, Belouettar S, Makradi A (2016) Influence of fluid flow and heat transfer on crack propagation in SOFC multi-layered like material with anisotropic porous layers. International Journal of Solids and Structures 78-79(October):189-198. https://doi.org/10.1016/j.ijsolstr.2015.08. 026

Smith MB, Montgomery CT (2015) Hydraulic fracturing. In: Hydraulic Fracturing. CRC Press. https://doi.org/10.1201/b16287

Țene M, Al Kobaisi MS, Hajibeygi H (2016) Algebraic multiscale method for flow in heterogeneous porous media with embedded discrete fractures (F-AMS). J Comput Phys 321(September):819-845. https://doi.org/10.1016/j.jcp.2016.06.012

Vidunas R (2008) "Identities between Appell's and hypergeometric functions." Kobe University, no 5: 1-30. https://doi.org/10.1016/j.jmaa. 2009.01.047

Wang K, Lou Z, Guan L, Zhang X, Qin B, Huang Y (2020) Experimental study on the performance of drilling fluid for coal seam methane drainage boreholes. Process Saf Environ Prot 138(June):246-255. https://doi.org/10.1016/j.psep.2020.03.041

Publisher's note Springer Nature remains neutral with regard to jurisdictional claims in published maps and institutional affiliations. 